University of Nebraska - Lincoln

DigitalCommons@University of Nebraska - Lincoln

$6-20-2020$

\title{
Psychological and neurobiological mechanisms underlying the decline of maternal behavior
}

Ming Li

Follow this and additional works at: https://digitalcommons.unl.edu/psychfacpub

Part of the Psychology Commons

This Article is brought to you for free and open access by the Psychology, Department of at

DigitalCommons@University of Nebraska - Lincoln. It has been accepted for inclusion in Faculty Publications, Department of Psychology by an authorized administrator of DigitalCommons@University of Nebraska - Lincoln. 


\title{
Psychological and neurobiological mechanisms underlying the decline of maternal behavior
}

\author{
Ming Li \\ Department of Psychology, University of Nebraska-Lincoln, Lincoln, NE, USA \\ Correspondence - 238 Burnett Hall, Department of Psychology, University of Nebraska-Lincoln, \\ Lincoln, NE 68588-0308, United States.email mli@unl.edu.
}

\begin{abstract}
The maternal behavior decline is important for the normal development of the young and the wellbeing of the mother. This paper reviews limited research on the factors and mechanisms involved in the rat maternal behavior decline and proposes a multi-level model. Framed in the parent-offspring conflict theory (an ultimate cause) and the approach-withdrawal model (a proximate cause), the maternal behavior decline is viewed as an active and effortful process, reflecting the dynamic interplay between the mother and her offspring. It is instigated by the waning of maternal motivation, coupled with the increased maternal aversion by the mother in responding to the changing sensory and motoric patterns of pup stimuli. In the decline phase, the neural circuit that mediates the inhibitory ("withdrawal") responses starts to increase activity and gain control of behavioral outputs, while the excitatory ("approach") maternal neural circuit is being inhibited or reorganized. Various hormones and certain monoamines may play a critical role in tipping the balance between the excitatory and inhibitory neural circuits to synchronize the mother-infant interaction
\end{abstract}

Keywords: Maternal behavior, Approach-Withdrawal, Parent-Offspring conflict theory, Oxytocin, Melanin-Concentrating hormone, Mesolimbic dopamine, Serotonin, Medial preoptic area, Prefrontal cortex

Published in Neuroscience and Biobehavioral Reviews 116 (2020), pp 164-181.

doi:10.1016/j.neubiorev.2020.06.009

Copyright (C) 2020 Elsevier Ltd. Used by permission.

Submitted 25 February 2020; revised 27 May 2020; accepted 5 June 2020; published 20 June 2020. 


\section{Introduction}

Parental behavior is the hallmark feature of all mammals. Despite its diverse characteristics, common psychological, hormonal and neuronal processes can be found in different types (altricial, precocial and semialtricial and semi-precocial) of parental behaviors and across different species. In the majority of mammals ( $>90 \%$ ), since only the female can lactate, it is the mother who provides much of maternal care and protection of the young. Thus, maternal behavior becomes the focus of analysis of parental behavior.

Several mammalian species have been studied extensively, namely the laboratory mouse, rat, rabbit, sheep and rhesus monkey. Each species has its advantages in regard to the analysis of genetic, hormonal, neuronal, individual, social and environmental factors that regulate maternal behavior. Among them, the laboratory rat is the best-studied mammal for the psychobiological analysis of maternal behavior (Lonstein et al., 2015). Researchers are attracted to this model for at least three reasons. First, as one of the earliest natural patterns of behavior to be studied in the laboratory, rat maternal behavior provides a behavioral model system to study basic psychological processes (sensorimotor function, attention, emotional processing, incentive motivation, and memory, etc.) and relevant neuroendocrinology (e.g., oxytocin, estrogen, progesterone, prolactin, etc.) and neurobiology (e.g., the hypothalamic nuclei, the mesolimbic dopamine system, etc.). Thus, historically, maternal behavior has attracted basic physiological psychologists who are interested in the biological aspect of behavior (Rosenblatt, 1990; Rosenblatt and Lehrman, 1963). Second, rat maternal behavior is an ecologically valid and complex social behavior that shares many features with human mothering behaviors, with common regulatory mechanisms (Fleming and Corter, 1988; Lonstein et al., 2015; Rosenblatt, 1989). Thus, it is attractive to psychologists who are interested in the neuroendocrine mechanisms involved in human parenting behavior, as well as biological psychiatrists who are interested in the neurochemical basis of postpartum mental disorders, such as postpartum depression, anxiety and psychosis (Fleming and Corter, 1988; Li and Chou, 2016; Rosenblatt, 1989). Accumulated knowledge on the hormonal control of rat maternal behavior over the years has provided a solid foundation for this scientific endeavor (Schiller et al., 2016). Third, maternal behavior in rats provides an interesting window into the effects of early life experience on the brain and behavioral development of offspring. Developmental psychobiologists and biological psychiatrists are interested in this behavior as they can use this model system to examine how the early life experience of the young and its alteration can influence the quality of mother-infant bonding, as well as the cognitive, emotional, behavioral, and social development of offspring and vulnerability to physical and mental illnesses (Champagne et al., 2008; Claessens et al., 2011). 
Rodent maternal behavior is one major behavioral pattern of a mature female. It consists of distinct phases lasting 3-5 weeks. The cycle of maternal behavior is a product of the maternal responsiveness of the mother and the developmental changes in the young. As pointed out long time ago by the "father of the experimental study of maternal behavior" (Fleming, 2007) Jay Rosenblatt (Rosenblatt, 1969), "there is no reason to believe that the psychophysiological basis of maternal behavior and factors which influence its development are the same during different phases. Each phase requires analysis of that phase, and the separate phases need to be related to one another in a developmental sequence" (page 37). Unfortunately, the vast majority of maternal behavior studies over past several decades has been focusing on the early phases of the maternal behavior cycle (e.g., initiation and maintenance) and their neural and endocrine mechanisms (Kohl et al., 2017; Numan, 1994; Numan and Young, 2016; Wu et al., 2014), while little experimental research has been devoted to the decline phase. One implicit assumption is that the decline of maternal behavior is a passive process. As the young become older, the stimulus characteristics of pups that used to elicit strong maternal responsiveness gradually disappear. Maternal behavior declines in response to this change of sensory characteristics and motoric response attainments (Reisbick et al., 1975). We take on a different view, and suggest that the maternal behavior decline is an active process, reflecting the dynamic interplay between the mother and her offspring. "Active" also means that it is an effortful endeavor, requiring the mother to withhold her caregiving behaviors, and reject any solicitation from the young. Multiple factors across the physical, psychological, hormonal and neuronal domains interact to influence the maternal behavior decline. This review focuses on the known factors involved in the regulation of rat maternal behavior decline and discusses the implication for understanding human parenting behavior and parenting disorders. To the extent that maternal behavior in rats shares features of maternal behavior common to all mammals, an analysis of the maternal decline in rats is relevant for the study of the maternal decline in human and other mammalian species.

Because properly managing the maternal behavior decline by the mother is not only critical for the development of the young and the mother's own physical and mental health, but also important for the optimal propagation of the genes of the parents, we believe that understanding how the maternal behavior decline is regulated behaviorally and neurobiologically is just as important as understanding how it is initiated and maintained. For the young, there is evidence showing that excess of maternal care leads to elevated anxiety and depression, impaired cognition and social skill development, and reduced explorative behavior in both animals (Farshim et al., 2016) and humans (Gere et al., 2012; McLeod et al., 2007). The "helicopter mom" phenomenon is no stranger to many of our readers and may reflect the 
failure of the mother to actively adjust her caregiving behaviors. On the other hand, weaning too early or deprivation of maternal care too early is known to cause various physical and psychological problems, including increased corticosterone secretion, dysregulation of feeding behavior, increased anxiety and stress responses in the young animals when they become adults (Kikusui et al., 2019; Tavares et al., 2020). Human children who experience maternal deprivation or neglect are also at greater risk to develop psychiatric illnesses in the future (Agid et al., 1999). For the mother, mothering requires a substantial allocation of physical (e.g., lactating, cuddling, moving around and diaper changing, etc.) and psychological (e.g., attention, learning, memory, executive functions) resources in order to ensure adequate nutrition, care and protection of the young. Thus, prolonged mothering imposes significant immediate costs and burdens for the mother, including disrupted sleep-wake cycles, eating habits, impaired attention and memory, depressive mood and elevated anxiety. From the evolutionary perspective, excessive devotion of energy and resources to the young who can survive on their own is not only wasteful, but also delays the mother's reproductive opportunity. Natural selection would work against such a trait, and favor individuals who can maximize their reproductive success. This pressure has been shaping the reproductive strategies among many mammals. One phenomenon illustrating this point is the "postpartum estrus", a brief period of ovulation and sexual receptivity which usually occurs immediately or shortly after parturition in many mammalian species (Gilbert, 1984), including rats (Connor and Davis, 1980; Uriarte et al., 2008), mice (Dewsbury et al., 1979), and rabbits (Martinez-Gomez et al., 2004). A female who conceives in postpartum estrus is able to gestate one litter while nurturing another simultaneously, effectively doubling its reproductive output and cutting the interval between successive litters by half (a typical interval is 25-30 days in rats). For this female, she must manage her energy expenditure properly throughout the postpartum period to ensure the proper growth of both litters. One important process that is favored by natural selection is to regulate the maternal care decline for the first litter, and simultaneously prepare for the birth of the second litter. Even for the females who fail to conceive during this period, managing the maternal behavior decline is also important. The female is in a lactational diestrus throughout the postpartum period. Until the litter is weaned, she is unable to resume her estrous cycle and conceive. Therefore, stopping maternal care (weaning) is an effective and necessary step in facilitating reproduction of the mother. These phenomena strongly suggest that from both the psychological and evolutionary perspectives, there is a pivotal point or time period in postpartum when the young must be weaned and the female is freed to reproduce. The goal of the current review is to shed light on the possible evolutionary, behavioral, hormonal, and neural mechanisms that govern the decline in maternal behavior. 
In this review, we start with a brief description of the rat maternal behavior cycle, and Robert Trivers's parent-offspring conflict theory. This theory provides an evolutionary explanation (the ultimate cause) of why the decline of maternal behavior should occur, and the necessity and benefit of the maternal behavior decline. We then discuss how the approach-withdrawal model, advocated by Rosenblatt and Mayer (1995) and others (Fleming et al., 1989; Numan, 2007; Pryce, 1992) to explain the onset of maternal behavior, can be extended to account for the decline of maternal behavior. This motivational model provides an excellent explanation of the proximate cause of maternal behavior decline. We then review limited research on the factors known to influence the maternal behavior decline in the rat. These factors include sensory and motor characteristics of the young, hormonal and neurochemical changes of the mother, and neural control of maternal responsiveness. Building upon early empirical and theoretical work (Moltz, 1974; Rosenblatt, 1969), we synthesized a framework and conceptualized the maternal behavior decline as an active and effortful process, reflecting the dynamic interplay between the mother and her offspring. It is instigated by the waning of maternal "approach" motivation, coupled with the increased maternal aversive ("withdrawal") motivation by the mother in responding to the changing sensory stimulations (e.g., visual, auditory, tactile, etc.) from the young. Neurobiologically, we hypothesize that the inhibitory neural circuit, including the olfactory bulb, medial amygdala, and dorsomedial and ventromedial hypothalamus, that is initially suppressed in the onset phase starts to gain control of maternal caregiving behaviors in the decline phase by inhibiting the excitatory maternal neural circuit (e.g., medial preoptic area, medial prefrontal cortex, the mesolimbic dopamine system). Neurochemically, we suggest that progesterone, melaninconcentrating hormone, and possibly other neurochemicals, such as prolactin and certain monoamines (dopamine and serotonin) via their receptors $\left(D_{1}, D_{2}\right.$ and $5-\mathrm{HT}_{2 \mathrm{~A}}, 5-\mathrm{HT}_{2 \mathrm{C}}$ ) play a role in the maternal behavior decline by tipping the balance between the excitatory and inhibitory neural circuits and synchronizing the mother-infant interaction. Finally, we propose an empirical approach on how to study the factors and mechanisms involved in the regulation of maternal behavior decline and suggest possible new lines of research, especially on the relevant neurochemical and neural basis. Although our theory is primarily built upon evidence from rat studies, it is in principle applicable to other mammalian species. We conclude this review by briefly discussing how our model can be applied to explain several human maternal care phenomena. Hopefully, this review will move us toward a more complete understanding of maternal behavior by integrating behavioral and biological changes across postpartum. 


\section{Maternal behavior consists of three distinct phases: initiation, maintenance and decline}

Early descriptive-functional studies have identified four principal components of rat maternal behavior: nursing or crouching over the young, retrieving pups to the nest, body and genital licking of pups, and nest-building. A female rat shows the full range of maternal behavior as soon as she gives birth. During parturition, the newly parturient rat rigorously licks the vaginal opening and helps the pups as they emerge from the birth canal. Once the pups come out, the mother rat (dam) tears off the membranes surrounding the fetuses, eats the placenta and licks the pups. At the end of the parturition, she reconstructs the nest, retrieves the displaced pups and gathers all the pups together in the nest site, and adopts a nursing posture over the pups (Dollinger et al., 1980; Rosenblatt and Lehrman, 1963). During late gestation the dam develops maternal aggression toward intruders and becomes most aggressive between days 1 and 5 postpartum (Mayer and Rosenblatt, 1987). Starting around day 12 postpartum, there is a decline in caregiving activities, as early postpartum dams spend more of their time with the pups in the nest, nursing and licking the pups, while late postpartum dams spend significantly less (Galef, 1981; Rosenblatt and Lehrman, 1963). Functional studies support the notion that these different forms of maternal behavior are important for the survival and development of the young. For example, early body licking and anogenital licking can modulate infant arousal and help urinate and defecate (Alberts and Gubernick, 1990). Body and anogenital licking also has long-term general and wide-ranging effects on offspring development, including the development of the hypothalamicpituitary-adrenal responses to stress in the offspring (Liu et al., 1997); hippocampal synaptogenesis and spatial learning and memory in the offspring (Liu et al., 2000); and later social and sexual behavior (Birke and Sadler, 1987). Mothers lick male pups more than female pups, which apparently contributes to the differentiation of male sex characteristics (Moore and Morelli, 1979). Nursing behavior not only provides milk, but also serves to warm the pups that lack the thermoregulatory ability in the first week after birth. Pup retrieval prevents the death of displaced pups due to lack of milk and warmth from the mother. In addition, pup retrieval also allows mothers to nurse all the young at the same time. Maternal aggression protects the young from possible injury by intruding animals.

The maternal behavior cycle of the rat develops during the course of the postpartum period on the basis of the interaction of hormonal and external stimulation. Although current view holds that postpartum maternal behavior consists of the two distinctive phases, onset and maintenance, with the former being hormonally dependent and the latter being pup stimulus-driven, 
experience-dependent, and hormonally independent (Numan, 1994), it might be more accurate to separate it into three phases, as advocated by Rosenblatt (Rosenblatt, 1969). The first phase extends from the $1^{\text {st }}$ to the $3^{\text {rd }}$ postpartum day and is termed the "initiation" phase. This is the period when the major components of maternal behavior are initiated and displayed at full force. For example, lactating is initiated by the mother in the nest. She picks the pups up, licks them and hovers over them to allow the young to locate a nipple and suck. Pup retrieval becomes more efficient over this period, as the mother is able to initiate and resumes retrieving more quickly. The female constructs a compact litter nest with high walls and a tunnel allowing the female to enter and exit the nest with minimal destruction to the structure. The "maintenance" phase starts on the $4^{\text {th }}$ day and ends approximately on the $13^{\text {th }}$ or $14^{\text {th }}$ day. During this phase, the mother rat maintains a high level of maternal caregiving behaviors and ensures adequate feeding of the young. Feeding can be found outside of the nest when the pups approach the female at a certain distance from the nest. Frequency of pup retrieval and pup licking is low relative to that seen in the initiation phase, mainly because the young can crawl out of the nest and crawl back, and this activity reduces the retrieval activity. It is also noted that the enclosure of the nest becomes larger and the height of the walls become lower. In both the onset and maintenance phases, it is primarily the mother who initiate maternal behavior, while the young are merely considered as passive recipients of care. The final stage of the maternal behavior cycle begins around the $15^{\text {th }}$ or 16th day and ends until the 3rd or 4th week of postpartum. This is the "decline" phase when maternal behavior declines in an orderly fashion: nest building declines first, followed by pup retrieval, and then nursing. By day 14 postpartum, retrieving rarely occurs as pups become more active. Nursing does not decline until 20 or 21 days postpartum. Weaning also occurs in this phase. This phase can extend into the 5 th week of postpartum if the young are allowed to stay with the mother (Cramer et al., 1990). During this phase, feeding is almost entirely initiated by the young, rather than the mother. It is often observed that the young follow the female, crouch under her and nuzzle at her mammary region. As weaning proceeds, the female may actively reject the feeding approach by the young by turning away from them, or by pressing her mammary region against the floor, or by standing against a wall with her mammary region out of the reach of the young (Rosenblatt and Lehrman, 1963) (see Fig. 1). The young are then forced to feed on their own with other sources of food. This phase sees that the young play a more active role in shaping the patterns of the mother-young interaction.

As will be discussed below, both the physical and behavioral changes of the young and the behavioral and neurohormonal changes of the female dictate the character of maternal behavior across different phases (Rosenblatt, 


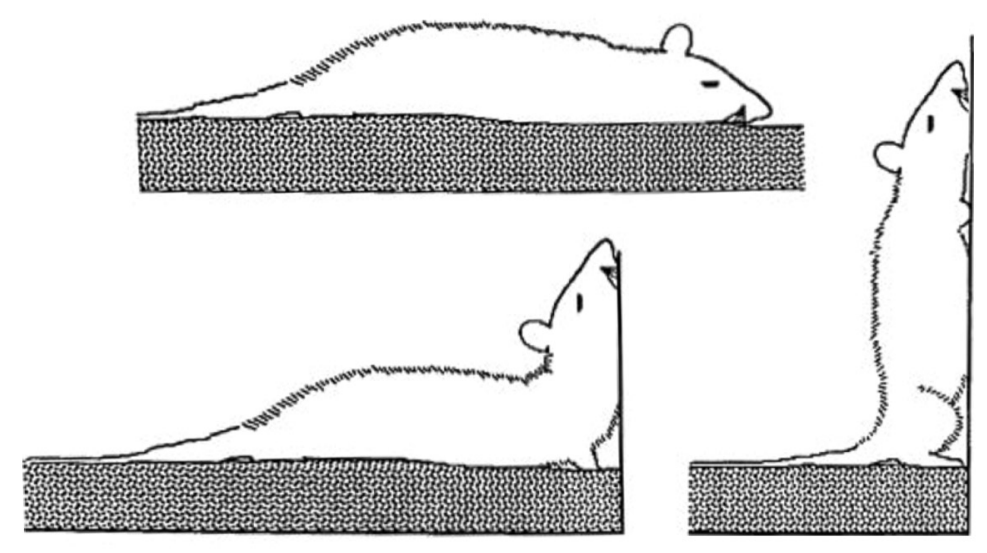

Fig. 1. Drawings of "press postures" that a mother rat engages in preventing suckling from the young. The original drawings appear as part of Figure 6 in Cramer et al. (1990), with permission from John Wiley \& Sons, Inc.

1969). Suffice to say that the phase transition reflects the interplay between these changes which are synchronized through certain behavioral and neural mechanisms. One important question is how much each party (the mother and young) contributes to this process. Before we discuss the various factors (proximal causes) that regulate the maternal behavior decline, we will briefly discuss the parent-offspring conflict theory (Trivers, 1974), which, in my opinion, provides an evolutionary explanation (the ultimate cause) of why maternal behavior declines throughout postpartum, and help understand the complex physiological or psychological mechanisms shaped by natural selection in the mediation of the maternal behavior decline.

\section{Parent-Offspring Conflict Theory: the ultimate cause of maternal behavior decline}

Parent-offspring conflict describes the evolutionary conflict between offspring and their parents over the amount and duration of parental care. Robert Trivers (1974) developed his influential theory of parent-offspring conflict based on the key concept of Hamilton's "inclusive fitness" and the assumption that the offspring play an active role in its relationship to its parents. Hamilton's "inclusive fitness" explained the evolution of altruistic behavior, which can be defined as any act that harms the individual who performs the act, while benefiting some other individuals, with "harm and benefit" being defined in terms of reproductive success. An altruistic act is predicted when benefit $(B)$ to the recipient, times the coefficient of relatedness $(r)$ from the 
helper to recipient, exceeds the cost $(C)$ to the helper, following the wellknown Hamilton's rule, $r \times B>C$. Maternal behavior is a perfect example of altruistic behavior, as it entails sacrifices of time, resources, and energy without immediate benefits for the mother. It is selected evolutionarily because it enhances the fitness of offspring to which the parent is genetically related. Maternal care increases the survival of the offspring, effectively enhancing the net reproductive success of the mother due to her $50 \%$ genetic relatedness to each of her offspring. This is especially true at the beginning of postpartum when the cost of mothering (time and effort devoted by the mother/survival and growth of the young) is low. For a mother rat, she is selected to distribute parental resources equally among all her pups in a litter. From the perspective of each individual pup, it should demand more investment and longer care than the mother is selected to give because this pup is $100 \%$ related to itself, but only partially ( $<=50 \%)$ related to its littermates or future siblings, so that it should continue to demand maternal care until the cost to the mother is at least more than twice the benefit to itself (assuming the offspring is $50 \%$ related to its littermates or future siblings). Assuming the $50 \%$ relatedness of the focal offspring and its sibling, Trivers (1974) pointed out that "there must occur a period of time during which $1 / 2<B / C<1$. This period is one of expected conflict between mother and offspring, in the sense that natural selection working on the mother favors her halting parental investment while natural selection acting on the offspring favors his eliciting the parental investment" (page 251).

Parent-offspring conflict is expected to result in offspring developing adaptations and strategies to extract more parental investment than the parent is selected to provide. Trivers (1974) discussed psychological tactics that the offspring employs to induce more investment than the parent wishes to give, including emitting more hungry signals and withholding satisfactory signals, or reverting to actions of an earlier stage of development. Parents are also selected to develop the ability to detect the use of these signals. Parental experience with preceding offspring is expected to improve the parent's ability to make the appropriate discrimination. Thus, the sensory and motoric characteristics of the young and maternal condition work together to determine the course of change in maternal care throughout postpartum.

The parent-offspring conflict theory can be easily applied to explain the maternal behavior decline. Trivers (1974) discussed that parentoffspring conflict is expected to increase during the period of parental care due to various changes occurring throughout the nursing period, including decreased chance of self-inflicted cost in the offspring, imperfect replenishment of parental resources in the parent, increasing size of the offspring, etc. As a result, the net reproductive success of the mother diminishes if she continues to nurse, and she should instead invest in herself and the next offspring. He 
pointed out that the detailed quantitative data from dogs, cats, rhesus monkeys, and sheep demonstrated that the behavior of both mother and offspring change throughout postpartum in a way consistent with the theory. He divided the period of postnatal maternal care into three phases according to the increasing age of the offspring. In the first phase, maternal care is initiated by the mother, who shows no avoidance behavior or aggression toward the infant. In the second, the mother and the offspring approach each other about equally, and the mother shows some avoidance behavior and some aggression in response to the infant's demands. The third phase can be characterized as the period of weaning. Most contacts are initiated by the offspring. Open avoidance and aggression characterize the mother. As mentioned above, a similar division of the postpartum maternal behavior cycle is also found in rodents (Konig and Markl, 1987; Rosenblatt, 1969).

In summary, the parent-offspring conflict theory provides an explanation of the ultimate cause of changes across the parental care period. It also sheds lights on the possible strategies that the parent and offspring may employ to resolve the conflict. The parent-offspring conflict theory is powerful in explaining many animal and human sociobiological phenomena, some of which will be a conflict of interests or outcomes discussed in the implication sections. It should be noted that "parent-offspring conflict" refers to a conflict of interest between the mother and her offspring arising from each party attempting to maximize its own inclusive fitness. As correctly pointed out by Rosenblatt (1990), it is not a behavioral term and cannot be used as an explanatory term with reference to the process of weaning in the rat and other animals. To explain the behavioral conflict often seen in litters in which the young try to solicit caregiving behaviors from the mother while she avoids and rejects them, we need to identify the distinct approach and withdrawal processes, as discussed below.

\section{The Approach-Withdrawal Biphasic Motivational Theory: the proximate cause of maternal behavior decline}

Life within social groups requires constant exchange of social signals among members. Change of maternal behavior throughout the postpartum period reflects this exchange process. Sensory and motoric signals from the young at their different developmental stages can alter the mother's responses towards them in different ways, while signals from the mother can also alter how the young approach and interact with the mother. As the frequency and intensity of maternal care undergo systemic changes throughout postpartum, from intensive caring (licking, nursing) to avoiding and withdrawal, what are the relevant behavioral mechanisms that mediate such changes in maternal responsiveness? Is there a common process that explains the onset, rising, maintaining and declining of maternal care? We think the 
answer is yes. It is the dynamic competition between two opposing motivational response systems, namely the maternal approach (i.e., maternal motivation) and neophobia-mediated withdrawal motivational systems in female rats that determines the phasic changes of postpartum maternal care to a great extent, from onset, to maintenance, and to decline (Rosenblatt and Mayer, 1995). Simply put, the onset of maternal behavior is facilitated when the approach responding to pup stimuli and engaging in maternal behavior becomes stronger than the avoidance or withdrawal response to such stimuli. The maintenance phase reflects the balance between these two systems, with the approach system slightly stronger than the avoidance or withdrawal system. During this period, the approach system gradually loses its strength, whereas the withdrawal system starts to gain strength. The decline phase is initiated when the withdrawal system becomes the dominant force and overcomes the impact from the approach system. This could happen when the withdrawal system increases in its strength (e.g., activity, energy), while the approach system decreases it. The dynamic interaction between the two opposing motivational systems in rats and the corresponding maternal phases are illustrated in Fig. 2. It should be noted that

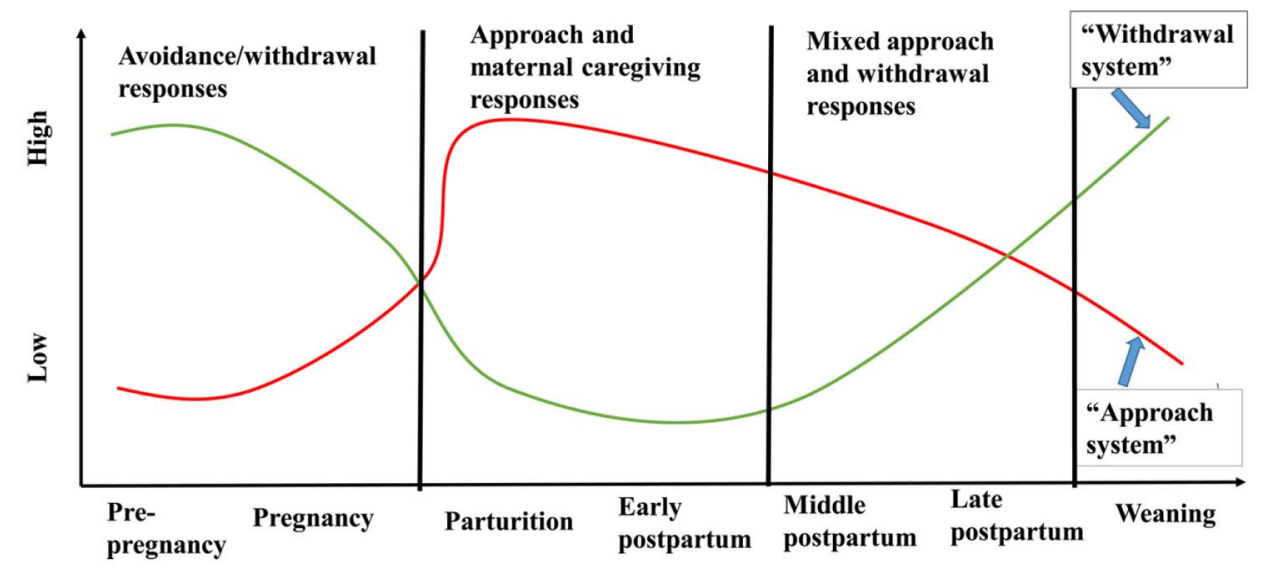

Fig. 2. The extended approach-withdrawal biphasic processes model. This model is based on the original idea articulated in Rosenblatt and Mayer (1995), and extended to explain the biphasic motivational changes ("approach" vs. "withdrawal") across the different reproductive stages. Before pregnancy, as seen in virgin rats, the neophobic withdrawal motivation is high, while the maternal "approach" motivation is low, resulting in various avoidance, withdrawal or even attack responses from virgin females upon being stimulated by pup stimuli. Throughout the pregnancy, the "approach" system gradually gain strength, while the "withdrawal" system loses its strength, especially towards the end of pregnancy. After parturition and throughout the early and middle postpartum phases (from postpartum day 1-15), the "approach" system dominates over the "withdrawal" system. In late postpartum, the "withdrawal" system becomes the dominant force and overcomes the impact from the "approach" system. 
Rosenblatt and Mayer (1995) originally proposed this approachwithdrawal biphasic model to explain the onset of maternal behavior in virgin females and first-time mothers for whom novel infant stimuli might elicit fear and withdrawal. Numan and Insel (2003) provided a comprehensive review of the evidence behind such a motivational model pertinent to the onset and maintenance of maternal behavior. Pryce (1992) proposed a similar systems model based on the approach and withdrawal framework but his model is still heavily focused on the early stage of the maternal behavior development. Here I argue that this model can be extended to account for changes across all three phases of maternal behavior cycle, that is, the same motivational processes (approach and avoidance/withdrawal) and their interactions not only promote and maintain the occurrence of maternal behavior, but also facilitate its decline. In this section, I will briefly summarize several key points of this approach-withdrawal model, and discuss how this model could be applied to explain the decline of maternal behavior.

Inspired by Tobach and Schneirla (1968), Rosenblatt and Mayer (1995) proposed that there exist two opposing motivational processes (approach and withdrawal) that organize an adult rat's responses towards pups. Upon being stimulated by pup stimuli, both processes are activated simultaneously but often not equally. This results in the predominance of one process over another at any given time. Pryce (1992)'s systems model is also built upon the idea of two opposing systems in the regulation of maternal motivation. He further divided the approach system into two subsystems: maternal attraction arousability and maternal anxiety arousability. The maternal attraction arousability responds to incentive salience of infant stimuli, while the maternal anxiety arousability responds to the aversive infant stimuli, such as distress call and certain facial expression. Thus, both serve to promote maternal behavior but through a positive and negative reinforcement mechanism respectively. Similarly, the withdrawal system also consists of two subsystems: maternal aversion arousability and novelty-fear arousability. Their activation reduces the likelihood of the female-infant interaction. At any given moment, which process (approach or withdrawal) dominates depends on the interaction between the characteristics of pup stimuli (e.g., young pups vs. old pups) and internal physiological and psychological conditions (e.g., hormoneprimed or not; stressed or not, etc.) of the adult. Such a view can be found in its origin in the traditional motivational theories, such as Bindra's united theory of emotion and motivation (Bindra, 1969), and Toates's systems motivational model (Toates, 1986).

The actual behavioral output (pup-directed and pup-related behaviors) depends on the dynamic competition between the approach and withdrawal systems. When approach and withdrawal are both strong and balanced, both approach and withdrawal responses can be seen, and the female may exhibit 
"stretched attention" (a behavioral element indicative of an approach-avoidance conflict) or alternating between approach and withdrawal responses. According to this theory, the onset of maternal behavior is the result of resolution of the competition between these two opposing forces with the approach system dominating over the withdrawal system due to the habituation of neophobic avoidance responses of the female. The existence of the withdrawal system has been well documented, and is mostly conspicuous when a virgin female rat is being exposed to pup stimuli for the first time. When foster pups are placed inside the cage of a female, she does not show immediate maternal behavior towards pups. Rather she avoids pups, stays away from them, and sometimes even attacks them (Fleming and Luebke, 1981). The female finds pups aversive as she is observed to push beddings towards pups to cover them and shows stretched attention posture. With continuous exposure, the fear-evoked avoidance and withdrawal subsides, while the pup incentive-elicited approach gains strength, tipping the balance towards the approach response and maternal care ensues. The approachwithdrawal model also suggests that parturitional hormones play a role in the onset of maternal behavior by influencing the resolution of conflicts between the approach and withdrawal systems. Evidence summarized by $\mathrm{Nu}$ man and Insel (2003) indicates that parturitional hormones can increase the attractive value and rewarding potential of pups to promote approaching behaviors. In the meantime, they reduce the aversive and fearful pup cues to suppress avoidance and withdrawal responses. Maternal experience, being ontogenetic, parturient or postnatal are thought to permanently alter the sensitivity and function of the approach and withdrawal motivational systems, both behaviorally and neurally, so that maternal behavior in different phases are more efficiently regulated.

It is important to note that the dynamic competition between the approach and withdrawal systems and its manifestation in behavioral outputs appear to be a universal feature of many mammals, not just of the rat (Pryce, 1992). For example, Hansen (1966) provided a vivid description of the transition of maternal responsiveness in rhesus monkeys. He observed that there is a general pattern regarding the relative frequency of positive (e.g., grooming, exploring, cradling, presenting and retrieving) and negative (e.g., threatening and punishing, including mouthing, cuffing, clasp-pulling, and rejecting) responses of mother monkeys toward their own and other infants. First of all, the mothers always respond more positively toward their own infants than to other infants. Secondly, the relative frequency of positive maternal behaviors is highest during the first month, then gradually declines. By the second month, positive and negative behaviors toward other infants are about equal. Toward their own infants, this balanced response occurs at a much later date, around the $8^{\text {th }}$ and $9^{\text {th }}$ month, then negative behaviors 
become increasingly more frequent for the first five months. Thirdly, there is a tendency for negative responses to become more severe as the infants grow older. Interestingly, later in the infant's life, punishment occurs without any provocation by the infant, suggesting that "maternal condition" may be responsible for this transition of maternal responses over the first year postpartum period. In humans, there might also be an innate avoidance or withdrawal system in addition to the apparent maternal approach system. Studies have shown that some first-time mothers do not experience maternal joy and affection after birth. One study showed that as many as $40 \%$ of first-time and $25 \%$ of second-time mothers recalled their predominant emotional reaction was feeling indifference when holding their babies for the very first time. This feeling was replaced by maternal affection in most mothers within a week of delivery (Robson and Kumar, 1980). Some mothers even have hostile feelings towards their infants, and wish that their babies have died or would die, or have been stolen (Brockington et al., 2006).

Rosenblatt and Mayer (1995)'s approach-withdrawal biphasic model is capable of explaining many phenomena related to the onset of maternal behavior in rats, such as pup sensitization; age, parity, and sex differences in maternal latency in juvenile, adult male and female rats; the facilitative effects of anosmia for the fast onset of maternal behavior during pup sensitization, etc. Here we show that this dual motivational theory can be easily extended to explain behavioral changes that occur during the decline phase of a maternal behavior cycle. Given the strong evidence supporting the possible universal existence of the approach and withdrawal systems in many mammals, and their roles in the regulation of the onset and maintenance of maternal behavior, this extension appears to be valid and is supported by empirical evidence showing that in the decline phase, the female rat is often observed to show less maternal caregiving behaviors and more withdrawal responses, such as actively rejecting pups by lying with nipples unavailable to the pups, darting-hopping, or shaking (Reisbick et al., 1975). These changes can be conceptualized as the withdrawal system increases in its strength while the approach system decreases; thus, the predominant behavioral responding pattern is organized by the avoidance system, resulting in a decline of maternal behavior. In the following, we will provide a summarized description of what we know about the stimulus characteristics of the young that promote the avoidance/withdrawal system, and the role of the mother in facilitating this process. Because the empirical research on this topic is very limited, we intentionally provide more experimental details than what are typically included in a review to show how the relevant studies are conducted and how future research could learn from them and address unanswered questions. 


\section{The stimulus characteristics of the young}

As pups mature from altricial neonates into active adult-looking young and self-feeding, drinking, grooming, and play-fighting become more frequent while suckling starts to decline, the mother adjusts her maternal activities accordingly. Thus, pup cues are critically involved in the regulation of maternal behavior decline in rats. On the one hand, removal of the young at birth effectively prevents the appearance of the cycle of maternal behavior which is normally observed during the 4 weeks following parturition. On the other hand, the decline of maternal behavior can be delayed by replacing the growing litter with new and young pups ( $<10$ days old), and younger pups are more effective in maintaining high maternal motivation than older ones (Wansaw et al., 2008). Observations such as these strongly suggest that the normal cycle of maternal behavior is heavily dependent on pup stimulation, and this stimulation can alter the female's postpartum caregiving behaviors through at least two modalities (Rosenblatt and Lehrman, 1963). The first one is the physical features of the pups. Certain features that formerly evoke maternal responses gradually disappear, while new features that inhibit maternal responses start to appear. A neonate with pink skin would certainly elicit a set of behavioral responses from the female quite differently from that elicited by a 16 days old pup with white fur. The second modality by which pup stimulation alters maternal behavior is the gained somatic capacities of the young. When a neonate can only show simple motoric reflexes, such as nuzzling and sucking to the female, the dam's responses, for the most part, are often independent of the neonate's behavior. It is the mother who initiates various maternal caregiving behaviors. After the second week, the pup can engage in a variety of social interaction with the mother, such as chasing, grooming and initiating nursing on its own, which in turn, elicit a wide range of social responses from the mother, among which maternal responses only consist of a smaller percentage. Apparently, each modality does not operate in isolation, thus the regulation of maternal behavior decline is the joint work of both.

Rosenblatt and Lehrman (1963) emphasized a distinction between two sources of pup stimulation on the development of the maternal behavior cycle. The first one is to induce "changes in the mother's physiological condition of readiness to perform maternal responses" (page 43), which they termed "maternal condition". I conceptualize this action of pup stimulation as an action on the physiological basis of "maternal motivation", the driving force to take care of pups. The physiological basis includes hormonal and neuronal activities involved in the support of maternal motivation. The second source of pup stimulation is to directly activate maternal responses. Rosenblatt and Lehrman (1963) described a study which, in my opinion, illustrates 
how the two sources of pup stimulation operate in the regulation of the development of the maternal behavior cycle. First, they permanently removed litters from two groups of ten females, one group on the $9^{\text {th }}$ after parturition, another one on the $14^{\text {th }}$ day. All females were then tested for maternal responsiveness to five 5-10 day-old pups at 2-day intervals until at least 20 days after parturition. They found that removal of the litter on the $9^{\text {th }} d a y$, when maternal responsiveness was still relatively high, maternal responsiveness declined earlier and to a lower level than in the case of those mothers who kept their young. This finding that removal of the mother's own pups in the maintenance phase facilitated the decline of maternal behavior suggests that pup stimulation from the litter functioned to support maternal responses. The decline of maternal behavior in the mothers who kept their litters (the normal litter situation, 9-12 pups) was at least partially due to reduction of pup stimulation's ability to support maternal behavior as the young get older (the first source). However, when the young were removed on the $14^{\text {th }}$ day, by which time maternal behavior already started to decline, this manipulation did not speed up the decline. Rather, certain maternal responses, such as pup retrieval were actually slowed down. This interesting and unexpected finding suggests that stimulation from the mother's own pups in the decline phase plays an active role in speeding up the decline process, and removal of this source of pup stimulation takes away this action (the second source). This simple experiment illustrates that although the two sources of pup stimulation on maternal behavior are impossible to be teased apart under normal circumstances, it is possible to see how they operate differently under certain experimental conditions, as their relative strength may vary in different phases of postpartum. One speculation is that the second source of pup stimulation (to directly activate maternal responses) operates preferentially in the onset and maintenance phases of the maternal behavior cycle to support maternal behavior, whereas it operates in the decline phase to suppress maternal behavior as a result of the changed characteristics of the young. However, although the first source (to alter "maternal condition") operates in the same fashion as the first one in the onset and maintenance phases to support maternal behavior, it may still operate to support maternal behavior in the decline phase. According to this idea, the decline of maternal behavior is the competition between these two sources of pup stimulation, with the first source to support and the second one to suppress maternal behavior. Future work is needed to provide more evidence on the interactive effect of pup stimulation (e.g., young vs. old pups) and maternal condition (e.g., females in early vs. late phases of postpartum) in order to determine the factors and processes involved in the regulation of maternal behavior decline. The experimental design advocated in this review might be one viable approach to achieve this goal (see Table 1). 
Table 1. A $2 \times 2$ complete factorial design with pup characteristics (young vs. old pups) and maternal condition (early vs. late postpartum) as two independent factors. Both maternal caregiving behaviors and withdrawal, rejection and avoidance behaviors are collected.

\begin{tabular}{|c|c|c|c|c|}
\hline \multirow{2}{*}{$\begin{array}{l}\text { Mother subjects } \\
\text { Testing pups }\end{array}$} & \multicolumn{2}{|c|}{$\begin{array}{l}\text { Early postpartum } \\
\text { (days } 4-8 \text { postpartum) }\end{array}$} & \multicolumn{2}{|c|}{$\begin{array}{l}\text { Late postpartum } \\
\text { (days } 13-17 \text { postpartum) }\end{array}$} \\
\hline & $\begin{array}{l}\text { Young pups } \\
\text { (4-8 days old) }\end{array}$ & $\begin{array}{l}\text { Old pups } \\
\text { (13-17 days old) }\end{array}$ & $\begin{array}{l}\text { Young pups } \\
\text { (4-8 days old) }\end{array}$ & $\begin{array}{l}\text { Old pups } \\
\text { (13-17 days old) }\end{array}$ \\
\hline Behaviors & $\begin{array}{l}\text { Maternal caring } \\
\text { behaviors }\end{array}$ & $\begin{array}{l}\text { Rejection/withdrawal/ } \\
\text { avoidance }\end{array}$ & $\begin{array}{l}\text { Maternal caring } \\
\text { behaviors }\end{array}$ & $\begin{array}{l}\text { Rejection/withdrawal/ } \\
\text { avoidance }\end{array}$ \\
\hline
\end{tabular}

Also, the findings of Rosenblatt and Lehrman (1963) need to be replicated, as Reisbick et al. (1975) did not find that retrieving, nursing and anogenital licking declined in tests with the younger (5-10 days old) pups after the $10^{\text {th }}$ days of postpartum. Therefore, available evidence is limited to allow us to specify the precise processes involved in the pup stimulation-induced maternal behavior decline.

Maternal behavior is under multiple sensory regulations. No single sensory modality is essential to the expression of maternal behavior. Similarly, no single sensory modality is essential to cause the decline of maternal behavior. However, the exact physical and behavioral characteristics of the young that influence the decline of maternal behavior have not been adequately explored and discussed. This is in sharp contrast to ample studies on the roles of stimulus characteristics of the young in the initiation and maintenance of rat maternal behavior, and there has been well conducted analysis of specific stimulus characteristics involved (Morgan et al., 1992; Stern, 1989, 1990; Stern et al., 1992; Stern and Kolunie, 1989, 1991). Certain features, such as visual (e.g., the appearance of fur), auditory (e.g., decreased ultrasonic vocalization calls), olfactory and tactile stimulation provided by the pups to the mother and their improved motor activities are thought to play important roles in the maternal behavior decline and the initiation of weaning, but the direct evidence is still very limited. We can only find one study that examined how specific pup stimulus factors such as age and motion (movement) regulate the decline in pup retrieval (Smith and Berkson, 1973). In this study, 20 Long-Evans black-hooded mother rats were tested with their own litters ( 8 pups) at 2, 5, 10, and 15 days postpartum. Each litter consisted of 4 sedated and 4 control pups, and the retrieval speed was calculated and analyzed. Based on the available evidence at that time, they expected that early in postpartum, the retrieval of active pups is more likely than retrieval of sedated ones because active pups provide more stimulation to the mother whose maternal motivation is high. Late in postpartum, 
sedated pups are expected to be retrieved first because pup movement at this time might inhibit maternal responses (Rosenblatt, 1969), and sedated pups resemble younger pups with respect to movement activity. They did find that on day 5 postpartum, active pups were retrieved faster compared to sedated pups and more mothers initially chose active over non-active pups. From days 5, 10-15 postpartum, the retrieval speed declined steadily, indicative of a reduction in maternal responsiveness with the increase of pup age and postpartum days. Critically, they did not find any difference in the retrieval speed between active and non-active pups on days 2, 10 and 15, and the preference for active pups also disappeared on these days. This finding seems to suggest that pup movement does not play a significant role in the inhibition of maternal responses, and other stimulus characteristics (such as auditory and olfactory cues, size, eyes open or closed, etc.) may be more important. The authors did point out that this effect of pup movement may not appear until after their last testing day (day 15 postpartum), thus, an extended testing period might be needed to detect this effect.

Maternal aggression and other active forms of maternal behavior are closely related during the cycle of maternal behavior, as they share a similar hormonal basis and may be similarly influenced by pup stimulus. Thus, understanding how pup stimulus affects the decline of maternal aggression might shed light on how it affects the decline of maternal caregiving behaviors. It is known that removal of pups from the nest results in a substantial decline in maternal aggressiveness. Following removal of the litter, maternal aggression can be readily elicited at $1 \mathrm{~h}$, but less at $5 \mathrm{~h}$ and totally absent at $24 \mathrm{~h}$ (Stern and Kolunie, 1993). The olfactory and auditory stimuli of pups appear to be critical in maintaining maternal aggression. When the litter is placed in a glass flask inside the home cage, maternal aggression is reduced substantially. However, when the litter is placed in a nylon mesh bag, maternal aggression persists (Ferreira and Hansen, 1986). These findings suggest that the olfactory and auditory stimuli of pups may also play a role in the maternal behavior decline.

Taken together, although it is well accepted that the sensory and motor characteristics of the young play an important role in the mediation of the decline of maternal behavior, questions still remain as to what specific sensory modalities and/or movement features are important and how they modulate the psychological processes of the mother to elicit changes in maternal responsiveness. As presented above in the framework of the extended approach-withdrawal theory, in the decline phase, the pup stimulus may stimulate the "withdrawal" motivational system while inhibiting the maternal "approach" system. In the next section, we discuss evidence showing how the "approach" and "withdrawal" motivational systems in the mother are altered in the decline phase of maternal behavior cycle. 


\section{Maternal condition}

There is observational evidence that mother rats play an active role in facilitating the decline of maternal behavior, as they start to withdraw from the pups to prevent the pups from attaching to a nipple by holding their ventral surface against either the floor or the walls of the cage ("pressing posture") (Cramer et al., 1990), and to actively reject them by various mild agonistic behaviors (see Fig. 1). Thus, to study maternal behavior decline, one thing we have to do differently from the study of the onset and expression of maternal behavior is to pay particular attention to withdrawal and rejection responses, in addition to monitoring the decline in maternal responses. Reisbick et al. (1975) classified the pup withdrawal and rejection behaviors into three categories: (1) "darting-hopping": sudden rapid running, hopping, or shaking movements by the female as well as wall climbing; (2) "rejection": kicking the pups with the hind legs, brushing them away with the body and forelimbs, pinning them to the floor with a forelimb, and lifting a pup in the mouth and tossing it to one side; (3) "withdrawal from pups": climbing to the top of the cage lid and perching there for long periods. An increase in these behaviors, coupled with a decrease in maternal responses, provides a more complete picture of the decline in maternal behavior. Other responses, such as pushing bedding towards pups to cover them, should also be collected as part of the avoidance and withdrawal responses (Rosenblatt and Mayer, 1995). The distance between the mother and pups might also be a sensitive measure of the avoidance and withdrawal responses (Fleming and Luebke, 1981).

One experimental way to isolate and estimate the contribution of changes in "maternal condition" to the maternal behavior decline is to test mother rats with the same age pups under the same condition every day throughout the postpartum period. Because the testing condition, including age of the pups, duration and sequence of the test, is the same every day, if there is any change in maternal behavior, it can only be attributed to changes in "maternal condition", that is, the hormonal, neuronal and psychological changes in the mother across the postpartum. Rosenblatt and Lehrman (1963) provided the first study of this kind. They used five 5- to 10-day-old foster pups as the standard pup stimuli, and tested 9 postpartum females starting on day 1 postpartum until day 28 . Each daily test included a 30-min test of nursing in the nest, followed by a 3-min test of retrieving, and 50-min test of nest building by allowing the female to collect nesting materials for $50 \mathrm{~min}$, and quality of the nest was rated next day. They found that nest building started to decline around the $13^{\text {th }}$ day, and disappeared by the $18^{\text {th }}$ day. Nursing and retrieving responses began to decline on the $14^{\text {th }}$ day. On the $21^{\text {st }}$ day, there was no retrieving, while nursing was only seen in one-third of the females. 
Interestingly, nursing and retrieving behavior, but not nest building, reappeared during the $4^{\text {th }}$ week. This study demonstrated that the decline of maternal behavior has a natural time course, and may reflect changes in the female's own "maternal condition", not merely passive reactions to the changing characteristics of the young. The reappearance of nursing and retrieving in response to the standard pup stimuli (5- to 10-day-old pups) after the typical weaning period (day 21-25 postpartum) is interesting as it may indicate the beginning of the next maternal behavior cycle. Once again, this finding further demonstrates that the female's own maternal condition is a critical factor in the control of maternal behavior.

As our extended approach-withdrawal theory would predict, at the psychological level, maternal behavior is mediated by the competitive action of the approach and withdrawal motivational systems. In the decline phase, the withdrawal system becomes the dominant force and overcomes the impact from the approach system. This means that we should see a reduction in maternal motivation, and a rise in withdrawal and avoidance motivation in the mother. Existing evidence appears to support this view. For example, Hauser and Gandelman (1985) used an operant response (i.e. lever-pressing) as a behavioral measure for maternal motivation. They tested postpartum female mice with 1 day-old pups daily for 20 days throughout the postpartum period, and found that operant responding for pups peaked in the first week of postpartum (day 4), started to decline around days 10-12, and then stabilized at the low level around day 18-20. Because the testing pups were always 1 day-old throughout the testing period, this work clearly shows that maternal motivation is reduced in the late stage of postpartum.

Wansaw et al. (2008) used a dual-choice conditioned place preference (CPP) paradigm to examine how maternal motivation changes from early postpartum (days 4-8) to late postpartum (days 12-16) in Sprague-Dawley rats. A CPP test is a classically paradigm used to assess incentive motivation for natural rewards (e.g., food, sexual partner, pups) or psychoactive drugs (e.g., nicotine, amphetamine, and cocaine). In a typical study, a subject animal is confined in one chamber of a three-chambered CPP apparatus (two side chambers connected by a central chamber) with a reward (e.g., pups), and another chamber without (e.g., pink rubbers) repeatedly for a few days. One day later, the subject is allowed to explore the entire apparatus and time spent in each chamber is recorded. CPP occurs when a subject spends more time in the reward conditioned chamber more than others. The dual-choice CPP is a new version of CPP in which two competing rewards are used in each side chamber to condition the subject to develop CPP to that chamber. It can be used to assess the relative strength of incentive motivation for one reward over another. Dr. Joan Morrell's group has used this CPP paradigm and determined the relative strength of incentive 
motivation for pups and cocaine across the early and late postpartum periods (Mattson et al., 2001). In Wansaw et al. (2008), they exposed early and late postpartum dams to competing pup stimuli (young vs. old pups) in a three-chambered CPP apparatus once a day for four consecutive days during postpartum days (PPD) 4-7 or 12-15, respectively. Each daily conditioning session lasted for $2 \mathrm{~h}$. One day after the last conditioning day (day 8 or 16 postpartum), dams were tested for their chamber preference for 60 min, with no pups present.

First, they found that the preferences for the pup-associated chambers were significantly higher during the early than the late postpartum when the dams were conditioned with pups that were age-matched to the postpartum days of the dams, confirming that maternal motivation is reduced in late postpartum relative to early postpartum. Second, $80 \%$ of the late postpartum dams actually preferred the object-associated chamber compared to $38 \%$ of the early postpartum dams, suggesting that the late postpartum dams may develop an avoidance or withdrawal reaction towards age-matched pups. In other words, they may start to treat old pups as aversive. Third, pup deprivation, a technique known to be effective in increasing maternal motivation (Hansen, 1994; Wu et al., 2016; Zhao and Li, 2009), had a dramatic effect in increasing the preference for pup-associated chamber only in the late postpartum dams, and the deprivation had to be for at least $22 \mathrm{~h}$. In contrast, this deprivation had little impact for the early postpartum dams, possibly due to already high levels of maternal motivation of early postpartum dams. In addition, late postpartum dams developed the preference for pup-associated chambers only when they were conditioned with younger pups, not age-matched old pups. These findings all support the notion that late postpartum dams are in a lower maternal motivation state than early postpartum dams are. Together, as the mother progresses through the postpartum period, her motivation to care for pups diminishes, while her motivation to withdraw from pups increases.

Reisbick et al. (1975) provides another piece of evidence showing that maternal withdrawal is indeed increased in late postpartum of the maternal behavior cycle. In that study, they compared sensitized virgins (females who become maternal after repeatedly being exposed to pups daily) with lactating mothers from the $10^{\text {th }}$ to the $28^{\text {th }}$ day (Reisbick et al., 1975). Both were tested daily first with the standard pups (5 pups aged 4-8 days), followed by the "live-in" pups that were matched with the postpartum days and increased in age by 1 day. They found that lactating mothers and sensitized virgins showed similar patterns of change in maternal responses to pups between the ages of 10 and 28 days. Nursing, retrieving and nest building declined throughout the testing period, starting around the $10^{\text {th }}$ and $12^{\text {th }}$ days. In the meanwhile, both groups increased their withdrawal and rejection responses 
after the $10^{\text {th }}-12^{\text {th }}$ day, especially in the virgin group. Both virgin and mother females were observed to reject pups by kicking the pups with the hind legs, brushing them away with the body and forelimbs, pinning them to the floor with a forelimb, and lifting a pup in the mouth and tossing it to one side. Sometimes the females climbed to the top of the feeder to withdraw from the pups. Also, older pups elicited more rejection and withdrawal responses than younger ones. When tested with young pups (4-8 days old), although nursing, pup retrieval and licking did not show a significant decline after the $12^{\text {th }}$ day, nest building in both groups did decline around the $13^{\text {th }}$ day, and pup retrieval latency was also significantly increased in the sensitized virgins. Also the percentage of the mothers and sensitized virgins lying in the nest with their nipples unavailable to the pups was significantly higher after the $16^{\text {th }}$ day. These findings not only show the reduction of maternal motivation throughout the postpartum period, but also the increase of maternal withdrawal and rejection, providing a strong support of the extended approach-withdrawal theory.

\section{Hormonal and neurochemical mechanisms involved in the maternal behavior decline}

In this section, we will discuss the possible involvement of various hormonal factors and neurochemicals in the regulation of the decline of maternal behavior. Much of our discussion is speculative, as we have very limited evidence that directly implicates parturition and lactation hormones or other neurochemicals in the maternal behavior decline.

Reisbick et al. (1975)'s finding that sensitized virgins and postpartum lactating mothers showed generally similar patterns of the decline of maternal behavior seems to suggest that parturition and lactation hormones such as estrogen, progesterone, prolactin and oxytocin are not involved. Those authors suggested that the decline of maternal behavior is nonhormonally mediated and pup stimulation alone plays a key role in this process. However, because this correlational study did not manipulate hormones in any stage of the postpartum period, the influence of these hormones on the decline process cannot be eliminated entirely. Theoretically, a hormone could impact the decline of maternal behavior in two distinct ways. One way is that the presence or higher level of this hormone hinders the decline process. From this perspective, estrogen, oxytocin and prolactin are speculated to be all involved in the maternal behavior decline, given their roles in promoting maternal behavior (Bridges et al., 1990; Fleming et al., 1989; Stolzenberg and Champagne, 2016). Their presence or elevation may hinder and delay the decline process by promoting active maternal care. This idea can be tested by administering an individual 
hormone or their combinations in late postpartum and see if maternal behavior is increased and the decline process is disrupted. Fortunately, nature has done the best experiments for us. As mentioned above, female rats and rabbits have a small time window in postpartum (postpartum estrus) when they can get pregnant again (Gonzalez-Mariscal et al., 2016; Martinez-Gomez et al., 2004; Uriarte et al., 2008). This enables them to gestate one litter while simultaneously nurturing another. Shortly after the second parturition, the first litter is in the late postpartum (the decline phase), while the second litter is in the early postpartum (the rising and maintenance phase) and the mother is still under hormonal influences. By examining how the postpartum females respond to their first litters (who are in late postpartum), we can assess the effects of lactation hormones such as estrogen, oxytocin and prolactin on the decline of maternal behavior. Although not designed to address this issue, Uriarte et al. (2008) did report that mother rats who take care of two litters simultaneously nursed and licked the first litters more than those who only cared for one litter. The litter received even more maternal stimulation when the second litter was present (Uriarte et al., 2014, 2008). This finding suggests that under natural conditions, parturition and lactation hormones do increase maternal care and can delay the decline of maternal responses towards the old pups, a finding consistent with our speculation.

Because postpartum estrogen and progesterone decline to virgin levels by 7 days postpartum in rats (Orpen et al., 1987), and oxytocin and prolactin also gradually decline with the intensity and frequency of lactating subside (Amenomori et al., 1970; Caughey et al., 2011; Escalada et al., 1996), the natural return of these hormones back to virgin levels may be required to allow the decline of maternal behavior to occur in late postpartum. This has been confirmed in maternal aggression by Caughey et al. (2011), who reported that the intensity of maternal aggression varied from late pregnancy until weaning: it first appeared at the end of pregnancy, peaked in the early postpartum period on PPD 4-7, dropped to a low level in the middle postpartum (PPD 14) before completely disappeared in late postpartum (PPD 21). Mirroring such a behavioral change, central oxytocin (OXT) receptor (OTR) and vasopressin (AVP) V1a receptor (V1a-R) binding in lateral septum and other regions also underwent similar changes through the peripartum period and were found to be positively correlated with the peak of maternal aggression, suggesting that oxytocin and vasopressin may be responsible for the change of maternal aggression from pregnancy till weaning. This kind of hormonal impact on the maternal decline is of clinical significance if the specific hormonal impact can be identified, as it may explain biologically why some mothers have a hard time reducing their maternal care when such care is no longer needed. 
The second way by which a hormone may influence maternal behavior decline is that the presence or higher level of such hormone facilitates the decline process. As the onset of maternal behavior in rats is critically dependent on the progesterone withdrawal, and high levels of progesterone hinder the onset and expression of maternal behavior, we speculate that higher levels of progesterone may function to facilitate the maternal behavior decline in late postpartum. One direct evidence coming from Nature also comes from the studies on postpartum estrus (Martinez-Gomez et al., 2004; Uriarte et al., 2008). The focus here is on the maternal effects of postpartum pregnancy of lactating mothers and how they differ from non-pregnant mothers. Uriarte et al. (2008) provided evidence suggesting that postpartum pregnancy and associated hormonal changes (presumably higher levels of progesterone) have a facilitative effect on the maternal behavior decline. Pregnant lactating rats spent more time outside the nest and less time nursing than nonpregnant mothers. After parturition, they also licked the newborn pups less than mothers with single litters. Hudson et al. (1996) reported that concurrently pregnant-lactating rabbits weaned the first litters earlier than they did with the second litters when they were not pregnant. González-Mariscal et al. (2009) found that maternal nest-building such as digging and strawcarrying were significantly reduced in pregnantlactating rabbits relative to pregnant-only ones. The pregnant-lactating rabbits also had a higher pup mortality rate than females raising nonoverlapping litters (Martinez-Gomez et al., 2004). Under the confined laboratory condition, they may even attack young attempting to suckle (Gonzalez-Mariscal et al., 2016). These findings suggest that pregnant hormones, especially progesterone, can inhibit maternal behavior and facilitate the weaning in rodents and rabbits.

Recently, Grieb et al. (2017) provided additional support for the facilitative effect of progesterone on the maternal behavior decline. They focused on the mid-lactation rise of ovarian-produced progesterone (postpartum days 10-12) in female rats and examined whether preventing the progesterone rise or inhibiting its function would enhance maternal activities in the midto-late lactation period. First, they found that ovariectomized dams licked, hovered over, and nursed pups in kyphosis more frequently than controls on postpartum days 7-18. Next, they administered progesterone receptor antagonist RU 486 to dams and observed that RU 486 treatment increased maternal activities compared to the control. They concluded that the natural rise of progesterone in the middle-to-late postpartum may limit the display of some maternal behaviors and contribute to their decline as weaning approaches. However, a direct test of this idea in rabbits by injecting progesterone ( $20 \mathrm{mg} /$ day) to lactating-only rabbits throughout the lactating days (1-30 or 1-23) failed to find any treatment effect on daily nursing behavior (Gonzalez-Mariscal and Gallegos, 2014). Also, Grieb et al. (2017) 
reported that in female rats, the numbers of progesterone receptor immunoreactive (PR-ir) cells in the MPOA and ventral bed nucleus of the stria terminalis (vBNST) (two brain regions critically important for maternal behavior) dropped from parturition to PPD 7 and remained low through PPD 18. It seems that if progesterone facilitates the decline of maternal behavior, PR-ir cells in the MPOA and vBNST should start to rise from the middle to late postpartum. Thus, future work should address this issue by focusing on whether and how progesterone and progesterone-mediated brain changes influence the maternal behavior decline. It is possible that PR-ir cells in other brain regions, especially those in the inhibitory neural circuit (see below) may increase to exert the maternal inhibition. This possibility needs to be further investigated.

Besides progesterone, another hormonal factor that may play such a facilitative role is the melanin-concentrating hormone $(\mathrm{MCH})$ (Benedetto et al., 2014). $\mathrm{MCH}$ is an inhibitory neuromodulator involved in homeostatic regulation and motivated behaviors. Most of the neurons containing $\mathrm{MCH}$ are located within the zona incerta, incerto-hypothalamic and lateral hypothalamic areas, but a small number of $\mathrm{MCH}$ neurons have also been found in the olfactory tubercle and the paramedian pontine reticular formation in male and female rats (Ferreira et al., 2017). Interestingly, expression of $\mathrm{MCH}$ depends on the sex and metabolic state of the animal. For example, $\mathrm{MCH}$ expression in the laterodorsal tegmental nucleus (LDT) is only found in female rats, and during lactation, this neuropeptide is also expressed in the medial preoptic area (MPOA) and the paraventricular hypothalamic nucleus (PVN) (Knollema et al., 1992; Rondini et al., 2010), brain regions critical for maternal behavior. One important observation is that $\mathrm{MCH}$ expression in the MPOA and PVN is progressively increased with the progression of lactation (Knollema et al., 1992), while maternal behavior declines progressively. Based on this observation of the negative correlation between $\mathrm{MCH}$ expression and maternal behavior, Benedetto, et al. (2014) suggesting that elevated activity of $\mathrm{MCH}$ neurons in the MPOA inhibits maternal behavior in the late postpartum period. They tested this idea by microinjecting $\mathrm{MCH}$ (50 and $100 \mathrm{ng} / 0.2 \mu \mathrm{l} /$ side) into the MPOA in postpartum female rats and tested their maternal behavior on postpartum days 5 and 6 . They found that $\mathrm{MCH}$ microinjection caused significant deficits in the active components of maternal behavior in early postpartum. This finding is in agreement with their hypothesis that $\mathrm{MCH}$ in the MPOA may contribute to the decline of maternal behavior and the weaning of maternal care. Rondini et al. (2010) showed that the majority of $\mathrm{MCH}$ neurons (> $95 \%$ ) in the MPOA are GABAergic, they may locally inhibit the projection MPOA neurons or they may inhibit their downstream neuronal targets (such as the anteroventral periventricular nucleus, AVPV and ventral premammillary nucleus, 
PMV) to inhibit maternal behavior (Rondini et al., 2010). Apparently, a more direct test of this hypothesis is to use $\mathrm{MCH}$ antagonists to treat the mother in late postpartum ( $>$ days 14 postpartum) and see if $\mathrm{MCH}$ antagonists can reverse the decline of maternal behavior. Another test is to use $\mathrm{MCH}$ in late postpartum females and see if it could facilitate the decline of maternal behavior. Evidence from these studies would help determine the contribution of $\mathrm{MCH}$ to maternal behavior.

Other than progesterone and $\mathrm{MCH}$, prolactin is another hormone that might be involved in the mediation of maternal decline. Circulating prolactin is high on postpartum days 4-10 when maternal motivation is high, declines sharply by postpartum day 12 , and is low on postpartum days 1221 when maternal motivation is also reduced (Taya and Greenwald, 1982). Thus, there appears to be a positive correlation between maternal motivation and prolactin levels in postpartum. Could it be possible that low levels of prolactin in late postpartum is one of the causal factors for low maternal motivation in late postpartum? As mentioned above, this idea can be tested in future research by administering prolactin in late postpartum and see if maternal decline is impaired. Like prolactin, oxytocin may play a similar role in the decline of maternal behavior because it is shown to mediate the synchronization of mother-infant interaction (Gordon et al., 2010). However, little is known about its specific role.

Research on the neurochemical basis of maternal behavior in rodents has highlighted the importance of brain monoamine systems, especially the dopamine and serotonin systems, in the regulation of the onset and early expression of maternal behavior. Overall evidence suggests that dopamine, acting upon ventral striatal $\mathrm{D}_{2}$ receptors, exerts a regulatory control over maternal responses by mediating the mother rat's maternal motivation (Byrnes et al., 2002; Keer and Stern, 1999; Numan and Young, 2016; Silva et al., 2001; Zhao and $\mathrm{Li}, 2009$ ), and serotonin, acting upon its $5-\mathrm{HT}_{2 \mathrm{C}}$ receptors in the VTA, plays a similar role (Gao et al., 2020; Pawluski et al., 2019; Wu et al., 2016). Specifically, blockade $\mathrm{D}_{2}$ receptors or activation of $5-\mathrm{HT}_{2 \mathrm{C}}$ receptors all leads to a decrease in maternal motivation. Thus, according to the extended approach-withdrawal model (i.e., an increase in withdrawal activity and decrease in approach activity), if the decline of maternal behavior in late postpartum is mediated by the decrease in maternal motivation, and shares some similarities to maternal behavior exhibited by mothers treated with $\mathrm{D}_{2}$ antagonists or $5-\mathrm{HT}_{2 \mathrm{C}}$ agonists, it would be tempting to speculate that dopamine and serotonin neurotransmission through striatal $D_{2}$ and VTA 5-HT ${ }_{2 C}$ receptors may undergo functional changes from early postpartum to late postpartum. $\mathrm{D}_{2}$ receptors might be decreased in late postpartum compared to early postpartum, while $5-\mathrm{HT}_{2 \mathrm{C}}$ receptors might be increased. We are not aware of any study that specifically examines $5-\mathrm{HT}_{2 \mathrm{C}}$ receptor functional 
changes throughout postpartum. However, there are several recent studies on the changes in dopamine signaling and dopamine receptors. One report shows that pup-elicited dopamine release in the nucleus accumbens (NAc) is significantly lower in late postpartum than in early postpartum (Pereira et al., 2013), a finding consistent with the motivational account of the maternal behavior decline. Recently, Winokur et al. (2019) examined changes in the activity of monoamine systems (dopamine, serotonin and noradrenaline) across the postpartum period in various brain regions, including the mesolimbic and mesocortical regions (nucleus accumbens, prefrontal cortex, dorsal striatum, etc.). They found significant changes in intracellular levels of monoamines and their turnovers from early (days 7-8 postpartum) to late (days 15-16 postpartum) and weaning stage of postpartum (days 25 postpartum) and these changes were region- specific. For example, they reported an increase of intracellular dopamine and serotonin levels and a decrease in their turnover within the dorsomedial striatum and nucleus accumbens core. Dopamine turnover was also increased in the medial preoptic area and nucleus accumbens shell from early postpartum to late postpartum, but decreased in the infralimbic medial prefrontal cortex, so was the level of serotonin (2019). Most recently, Grieb et al. (2020) employed two approaches to test the hypothesis that reduced expression of active maternal caregiving behaviors in the late postpartum period is partly due to decreased dopaminergic signaling. In their pharmacological study, they treated Sprague-Dawley (SD) mother rats with either vehicle, $\mathrm{D}_{1}$ receptor agonist $\mathrm{SKF} 38393$, or $\mathrm{D}_{2}$ receptor agonist quinpirole, or both agonists twice daily from postpartum days 9-15 and determined whether activation of dopamine $\mathrm{D}_{1}$ and/or $\mathrm{D}_{2}$ receptors would prevent the natural decline in maternal caregiving behaviors of late postpartum. The majority of mother rats repeatedly treated with SKF38393, or SKF38393 + quinpirole, and to a lesser extent those treated with quinpirole alone, maintained a significantly higher level of maternal caregiving behaviors when compared to the vehicle-treated females, whose caregiving declined more rapidly during the late postpartum period. In their molecular study of dopamine $\mathrm{D}_{1}$ and $\mathrm{D}_{2}$ receptor gene expression, tyrosine hydroxylase levels ( $\mathrm{TH}$; the rate-limiting enzyme in DA synthesis) and dopamine turnover, they reported that in Long-Evans (LE) rats, $\mathrm{D}_{2}$ receptor mRNA levels (not $\mathrm{D}_{1}$ ) in both the nucleus accumbens shell (NAc shell) and VTA were significantly lower in the late postpartum (PPD 18) compared to early postpartum (PPD 7). Also, levels of TH immunoreactivity in the VTA were significantly lower in the late postpartum (PPD 18) compared to early postpartum (PPD 7). In this study, they did not find any change in 5-HT, 5-HIAA, or 5-HT turnover across different stages of postpartum. These findings indicate that reduced dopamine $\mathrm{D}_{1}$ and $\mathrm{D}_{2}$ receptor-mediated neuronal signaling in the mesolimbic dopamine pathway during mid-to-late postpartum is 
likely involved in the normal decline of maternal behavior, although there are conflicting findings regarding the specific dopamine receptors $\left(D_{1}\right.$ vs. $\mathrm{D}_{2}$ ) and their roles in the maternal behavior decline. Future work needs to further determine the specific roles and dynamic changes of various dopamine and also serotonin receptors using various behavioral and neuroscience tools in different stages of postpartum.

Taken together, the hormonal and neurochemical mechanisms underlying the decline of maternal behavior in late postpartum are less understood compared to our understanding of the pup stimulus control of maternal behavior. Parturition and lactation hormones may be involved, but the specific mechanisms are unknown. The brain monoamine systems are likely to play an important role in the regulation of maternal decline, given that they are sensitive to maternal experience and can undergo plastic changes across the postpartum period. The most likely neurochemical mechanisms underlying the maternal behavior decline involve multiple neurochemicals, such as dopamine and serotonin and their interactions with various hormones, such as oxytocin and prolactin. This would be a fruitful area for future research.

\section{Neural basis of the maternal behavior decline}

\subsection{The two neural circuits that mediate the "approach" and "withdrawal" responses}

As our extended approach-withdrawal theory would suggest, the decline of maternal behavior results from the dynamic competition between the two opposing behavioral response systems when the avoidance/withdrawal/rejection system increases in its strength, while the approach system decreases it. Correspondingly, the putative neural substrate underlying the maternal decline likely involves two functionally opposing neural circuits, with one supporting the approach system and another one supporting the withdrawal system. Extensive research on the neuroanatomical basis of maternal behavior in rats has demonstrated that there are indeed two distinct neurocircuits that govern the approach and withdrawal responses (Numan, 2015).

\subsubsection{The excitatory "approach" neural circuit}

The putative "approach" neural circuit centers around the hypothalamic medial preoptic area (MPOA) and the adjoining ventral bed nucleus of the stria terminalis (vBNST), and their reciprocal projections to the nucleus accumbens (NAc), VTA, paraventricular hypothalamic nucleus (PVN), and periaqueductal grey (PAG) (Kohl et al., 2018; Kohl and Dulac, 2018; Numan, 2015; Numan and Insel, 2003). This circuit is essential for the onset and early expression of all aspects of maternal behavior (i.e., pup retrieval, pup 
licking, nursing, etc.) and maternal motivation in maternally behaving rodents (e.g., primiparous and multiparous females, sensitized adolescent and adult virgin females and males, etc.) (Pereira and Ferreira, 2016). The critical component of this circuit is the MPOA, as disruption of MPOA function or its communication with other components of the maternal approach circuit (e.g., lateral preoptic area, vBNST, NAc, VTA etc.) severely impairs maternal behavior. It is also the primary site where parturitional hormones act upon to drive maternal behavior via hormonal receptor-mediated mechanisms, as MPOA contains receptors for all the hormones involved in the rapid onset of maternal behavior, including receptors for estradiol, prolactin, and oxytocin. Maternal experience gained through motheryoung interaction that is critical for the maintenance of maternal care also induces various long-term plastic changes in this region (Featherstone et al., 2000). The MPOA's communication with the mesolimbic dopamine system is particularly important for maternal motivation, consistent with the well documented role of dopamine in reward processing and incentive motivation (Berridge, 2007; Berridge and Robinson, 1998). Functional disturbances of the mesolimbic systems, either enhancing or suppressing dopamine neurotransmission, disrupt maternal behavior, especially the active components of maternal behavior (e.g., pup retrieval, licking), but not passive ones (e.g., high-arched-back nursing) (Hansen, 1994; Li, 2015; Li and Fleming, 2003; Olazabal et al., 2013; Pereira and Ferreira, 2006; Pereira et al., 2005; Stern and Keer, 1999; Stolzenberg and Numan, 2011; Zhao and Li, 2009). One influential model proposed by Michael Numan suggests that multimodal pup stimuli processed and integrated in the medial prefrontal cortex ( $\mathrm{MPFC}$ ) activates MPOA neurons that express receptors to parturitional hormones (estrogen, progesterone, oxytocin, etc.) to stimulate maternal behavior. These neurons project to the VTA, causing an increase in dopamine release into the NAc. Dopamine acts upon its receptors $\left(D_{1}\right.$ and $\left.D_{2}\right)$ on the medium spiny neurons in the NAc to suppress the inhibitory GABAergic projections to the ventral pallidum (VP), allowing motoric responses to pups to occur. The MPOA also projects to the PAG and the brainstem (ventral pons and medulla), which then relay to the spinal cord nuclei to regulate stereotyped and reflexive aspects of maternal responses such as high arched-back nursing (Lonstein and Stern, 1997a, b). Olfactory, gustatory, and somatic sensory stimuli from pups can also be directly relayed to the NAc and VP via the glutamatergic excitatory efferents from the basomedial and basolateral amygdala (BMA/BLA) (Numan et al., 2010), in addition to the MPFC-MPOA pathway.

Recent studies employing advanced optogenetic and chemogenetic techniques have identified several neuronal populations in the MPOA in laboratory mouse are particularly important to generate maternal responses, including Galanin-expressing $\left(\mathrm{Gal}^{+}\right)$neurons (Kohl et al., 2018; Wu et al., 
2014), estrogen receptor $\alpha$ (Esr $1^{+}$)-expressing neurons (Fang et al., 2018; Wei et al., 2018), and Vgat $^{+}$(vesicular GABA transporter) neurons (Li et al., 2019). Fang et al. (2018) identified a projection from the MPOA Esr1 ${ }^{+}$neurons to the VTA non-dopaminergic cells that is critical for driving pup approach and pup retrieval, and that VTA dopaminergic cells are reliably activated during those behaviors. Li et al. (2019) further identified that there are two distinctive groups of Vgat $^{+}$neurons in the MPOA that mediate pup retrieval and maternal nest-building separately. The MPOA Esr1 ${ }^{+}$neurons, which make up $\sim 50 \%$ of the MPOA Vgat ${ }^{+}$neurons, are specifically involved in promoting pup-retrieval, whereas the non-Esr $1^{+}$Vgat $^{+}$neurons are important for nest-building behavior.

In the rostral part of the MPOA, there is a group of neurons in the anteroventral periventricular nucleus (AVPV) of the mouse hypothalamus that express tyrosine hydroxylase $\left(\mathrm{TH}^{+}\right)$. A recent study shows that these $\mathrm{TH}^{+} \mathrm{AVPV}$ neurons are preferentially involved in the regulation of maternal behavior in females (Scott et al., 2015). Mechanistically, AVPV $\mathrm{TH}^{+}$neurons relay a monosynaptic input to oxytocinexpressing neurons in the PVN and control oxytocin release when activated. It is possible that they mediate parental behavior by directly influencing oxytocin release. Another possibility is to regulate the MPOA, as AVPV $\mathrm{TH}^{+}$neurons have the densest projections to the MPOA.

In summary, the excitatory "approach" neural circuits involved in the stimulation of maternal behavior are complex, consisting of several sub-circuits, within the MPOA or scattered in other parts of the hypothalamus (e.g., AVPV, vBNST, etc.). Each sub-circuit may be specialized for a certain type of maternal responses (e.g., pup retrieval vs. nest building). The current understanding is that after being primed by hormones and neuropeptides, certain types of MPOA neurons (e.g., $\mathrm{Gal}^{+}, \mathrm{Esr}^{+}$) and $\mathrm{TH}^{+} \mathrm{AVPV}$ neurons are being activated by pup stimulation, which in turn, activate oxytocinergic neurons in the PVN to increase oxytocin release and prepare the brain and body for maternal care. The MPOA and AVPV neurons interact with other components of the excitatory neural circuit to drive maternal behavior. For example, they may engage in processing pup cues by interacting with the MPFC and amygdala; in generating maternal motivation signals by interacting with the VTA and NAc; and in executing and temporally organizing maternal responses by interacting with the $\mathrm{MPFC}, \mathrm{VP}$ and PAG, etc.

\subsubsection{The inhibitory "withdrawal" neural circuit}

Much evidence in support of the existence of an inhibitory maternal neural circuit comes from studies on virgin female rats, as virgin females do not respond maternally to foster pups upon initial exposure. They stay away from the pups, sometimes even attack the pups. It generally takes 5-7 days of continuous pup exposure (a process termed pup sensitization) for virgin 
rats to display maternal behavior (Fleming and Rosenblatt, 1974a; Rosenblatt, 1967). Evidence suggests that virgin females find pups aversive and fearful, and they have to overcome their fear in order to display maternal behavior (Fleming et al., 1989; Fleming and Luebke, 1981). The delayed onset maternal behavior in virgins is in sharp contrast to the immediate onset in parturient females, strongly suggesting that there exists an intrinsic system that exerts an inhibitory action on the "approach" maternal circuit. The putative inhibitory neural circuit that mediates the "withdrawal" response consists of the main (MOB) and the accessory olfactory bulbs (AOB), the medial amygdala (ME), dorsomedial and ventromedial hypothalamus (DMH and $\mathrm{VMH}$ ) that are thought to be suppressed by parturitional hormones around the time of parturition in order to allow the immediate onset of maternal behavior. Sheehan, Cirrito, et al. (2000) demonstrated that there were more Fos activations (more neuronal activity) in the medial amygdala and several medial hypothalamic sites in non-maternal rats than in maternal rats. The amygdala receives inputs from both main and accessory olfactory bulbs and projects directly to the MPOA and the VMH. The VMH also projects to the MPOA/vBNST. It has been found that activation of the olfactory systems increased medial amygdala neuronal activity, whereas stimulation of the medial amygdala predominantly inhibits MPOA neurons and also inhibits the onset of maternal behavior (Gardner and Phillips, 1977; Morgan et al., 1999). Critically, damaging each component of the neural pathway (OB-MEVMH) system or inhibiting neural activities of this system leads to the fast onset of maternal behavior in virgin rats (Fleming, 1987). For example, removal of main or accessory olfactory input facilitates the expression of maternal behavior in virgin animals (Fleming and Rosenblatt, 1974b, c). Lesions of the medial amygdala, the stria terminalis (the major efferent pathway from the medial amygdala), or the VMH result in the disinhibition of maternal retrieving and crouching in virgin animals exposed to foster pups (Bridges et al., 1999; Fleming et al., 1979, 1992; Fleming et al., 1980; Numan et al., 1993). The same facilitative effect can also be achieved by infusing oxytocin in the olfactory bulb (Yu et al., 1996). On the other hand, infusions of an oxytocin antagonist markedly delayed the occurrence of all components of maternal behavior in postpartum female rats (Yu et al., 1996). Virgins sustaining amygdala lesions differ from controls in not withdrawing from pups and in maintaining closer proximity to them, and they are less fearful in a series of emotionality tests (Fleming and Luebke, 1981). Neurotoxic lesions of DMH and VMH can also advance the onset of maternal behavior in primigravid rats (first-time pregnant rats) (Mann and Babb, 2004). Applications of various doses of neuropeptide K (NPK) into the VMH are found to be inhibitory to the occurrence of maternal behavior (Sheehan and Numan, 1997). The inhibitory effect of the VMH on maternal behavior might 
be related to its role in mediating avoidance, aggressive and defensive behaviors (Wang et al., 2015). One critically important finding is that the facilitation of maternal behavior produced by amygdala lesions can be abolished by lesions of the MPOA, confirming that the input from the amygdala acts through MPOA to exert its inhibitory role in maternal behavior (Fleming et al., 1983). It is highly possible that the inhibitory neural circuit mediates the maternal "withdrawal" responses (even the decline in maternal activity in late postpartum) by inhibiting the neuronal activities in the excitatory neural circuit.

Recent neuroscience research has identified other sources of inhibition. $\mathrm{Li}$ et al. (2019) reported that in mice, AGRP-expressing neurons ( 20,000) in the arcuate nucleus (ARC) of the hypothalamus form inhibitory synapses onto $\sim 30 \%$ neurons in the MPOA. They found that optogenetically stimulating AGRP neurons or stimulating AGRP projections to the MPOA selectively decreased maternal nest-building, but not pup retrieval. This inhibition of maternal nest building was achieved by the inhibition of MPOA neurons that express Vgat (MPOA Vgat $^{+}$neurons), the population targeted by AGRP terminals, as chemogenetic inhibition of this group of neurons also decreased maternal nest-building. Thus, AGRP neurons in the arcuate nucleus can inhibit maternal nest-building through direct projections to the MPOA. Because activation of AGRP neurons stimulates feeding behavior (Aponte et al., 2011), it is thought that AGRP neuronal activation-induced inhibition of maternal nest building may be related to the nonspecific effect of hunger on maternal care. In late postpartum, mothers need to spend more time on feeding in order to meet the demand from the growing pups, thus their AGRP neurons may need to be recruited to support feeding behavior, which in turn could lead to the inhibition of maternal nest building. From this perspective, we speculate that increased activity of AGRP neurons could be one possible mechanism responsible for the maternal behavior decline in late postpartum.

In summary, evidence collectively suggests the performance of maternal behavior is under the joint control of two antagonistic neural systems: the excitatory system, which mainly constitutes the efferents from MPOA/ vBNST neurons to various brain areas; and the inhibitory system, which consists of the $\mathrm{OB}, \mathrm{ME}, \mathrm{DMH}$ and $\mathrm{VMH}$ regions and their projections to the MPOA/vBNST. Both systems are plastic and sensitive to changes of the neuroendocrine systems and pup characteristics, as well as maternal experience. This neural organization is consistent with the approach-withdrawal theory (Rosenblatt and Mayer, 1995; Schneirla, 1959). However, the more critical question is: throughout the postpartum period, what are the relevant functional and structural changes in both systems that can account for the decline and ceasing of maternal behavior? 


\subsection{The dynamic changes of the "approach" and "withdrawal" neural cir- cuits throughout the postpartum period}

If the onset and early expression of maternal behavior require the dampening of the inhibitory neural circuit that subserves avoidance and defensive responses, in conjunction with amplification of the excitatory neural circuit that mediates approach and acceptance responses, the opposite changes might have to happen in the process of maternal behavior decline: an amplification of the inhibitory neural circuit together with a dampening of the excitatory neural circuit. Do we have evidence for these?

Regarding the amplification of the inhibitory neural circuit in late postpartum, we are not aware of any study that has monitored and compared neuronal activity of the inhibitory neural circuit in different phases of the maternal behavior cycle. Also, there is no study that has manipulated the components of the inhibitory system (e.g., $\mathrm{OB}, \mathrm{ME}, \mathrm{DMH}$ and $\mathrm{VMH}$ ) in late postpartum. Our prediction is that amplification of the inhibitory neural circuit in late postpartum will increase the avoidance and withdrawal responses from the mother, while decreasing various components of maternal behavior, thus speeding up the maternal behavior decline. Conversely, suppression of the inhibitory neural circuit will have an opposite effect on the two categories of behavioral responses and will delay maternal behavior decline. This would be an interesting area for future research. Regarding the dampening of the excitatory neural circuit in late postpartum, there is evidence showing that the MPOA does undergo a functional reorganization in late postpartum, changing its role from a stimulatory site to an inhibitory one. Pereira and Morrell (2009) inactivated the MPOA of mother rats on either day 7-8 or day 13-14 postpartum and tested their maternal behavior towards their own pups. In order to inactivate the MPOA, they used $2 \%$ bupivacaine, and found that when the injections were performed on day 7-8 postpartum, bupivacaine disrupted pup retrieval, licking and nest building. However, the same injections actually enhanced maternal behavior when they were performed on day 13-14 postpartum, at a time when maternal behavior remained at lower levels compared to those on day 7-8 postpartum. Pereira and Morrell (2009) proposed that the functional role of the MPOA is changed over the course of the postpartum period, from an early maternal excitatory role to a late inhibitory one. Thus, Pereira and Morrell (2009) maintains that the decline of maternal behavior in late postpartum is still mediated by the MPOA. Numan (2015) offered a different explanation. He pointed out that because bupivacaine may also inhibit fibers of passage through the MPOA, in addition to suppress the MPOA neuronal activity, maternal behavior might have been enhanced in late postpartum not because of the suppression of MPOA neurons but because of depression of an inhibitory system whose axons pass 
through the MPOA. Future work needs to address where this late inhibition of the MPOA is originated (i.e., functional reorganization of the MPOA itself or enhanced inhibition of the inhibitory neural circuit). Based on the above mentioned finding that $\mathrm{MCH}$ microinjections into the MPOA in early postpartum suppress maternal behavior, one interesting possibility is that the maternal decline is mediated by the elevated $\mathrm{MCH}$ in the MPOA in the late postpartum, which could also contribute to the changed role of the MPOA in maternal behavior (Benedetto et al., 2014).

Another area that may exert different functions on maternal behavior in early versus late postpartum is the MPFC. This region is well known for its a central role in top-down control of many higher-order functions, such as working memory, attention, emotion regulation, inhibitory control, and cognitive flexibility (Anastasio et al., 2015; Moghaddam and Homayoun, 2008; Puig and Gulledge, 2011; Puig et al., 2015). It is densely interconnected with numerous cortical and subcortical structures, including the MPOA, VTA, NAc and dorsal raphe (DR) (Holschbach et al., 2018), part of the excitatory maternal neural circuit. The robust anatomical and functional interconnections between the MPFC and the excitatory neural circuit suggest that the MPFC could play a role in maternal behavior through different behavioral mechanisms, including the executive control and organization of maternal activities and the regulation of dopamine-mediated maternal motivation (Afonso et al., 2007; Hansen, 1994; Li, 2015; Li and Fleming, 2003; Olazabal et al., 2013; Pereira and Ferreira, 2006; Pereira et al., 2005; Stern and Keer, 1999; Zhao and Li, 2009). With the progression of postpartum, the mPFC may undergo a significant change in responding to changed pup characteristics and maternal condition. Pereira and Morrell (2011) reported a preliminary study on this issue. They used bupivacaine to reversibly inactivate three distinct subregions of the MPFC: anterior cingulate (Cg1), prelimbic (PrL), infralimbic (IL) (Heidbreder and Groenewegen, 2003), and tested maternal behavior in early (days 7-8 postpartum) and late postpartum (days 13-14 postpartum). During the early postpartum, they found that transient inactivation of IL subregion severely disrupted all components of maternal behavior, whereas inactivation of PrL subregion had no effect. During the late postpartum, an opposite behavioral pattern was found: transient inactivation of the IL subregion had no effect on maternal behavior, whereas inactivation of PrL severely disrupted it. These findings seem to suggest that the IL subregion of $\mathrm{MPFC}$ is critical for early postpartum maternal behavior, whereas the PrL subregion is important for late maternal behavior. Pereira and Morrell (2011) suggested that as the postpartum period progresses and pups grow older, the maternal stimulatory role of the IL subregion gradually shifts to the PrL, and this change might be related to the transition from goal-directed responding to habitual responding. According to this view, the 
decline of maternal behavior in late postpartum might not be due to the dynamic competition between the excitatory and the inhibitory neural circuit, rather, the same neural regions (mainly different subregions of the MPFC and MPOA) change their roles through functional reorganization, emphasizing the central role of the MPOA and PrL in this process. One major source of such a functional reorganization is the maternal experience-induced neuroplasticity. However, evidence so far in support of this view is based on the reversal inactivation technique. As mentioned above, this technique cannot distinguish the role of intrinsic neuronal activity from that of the extrinsic fibers of passage. Thus, even if there is a functional change of a particular brain region across postpartum, it is still not clear whether this changed function is originated from the altered neuronal function at that particular site (e.g., MPOA) or from other brain regions (e.g., ME, VMH, dorsal raphe) that project to that site. Therefore, the detailed forms of functional changes are still awaiting to be discovered. It should be noted that the two possibilities are not mutually exclusive, as the changed function of a brain region can be induced by both.

\section{The model}

The model shown in Fig. 3 is a theoretical framework which explains the regulatory factors and neural networks involved in the regulation of the maternal behavior decline. Based on the literature review presented above, we propose that the maternal behavior decline in late postpartum towards weaning is an active and effortful process, reflecting the dynamic interplay between the mother and her offspring. We argue that the decline in maternal care is instigated by the waning of maternal ("approach") motivation, coupled with the increased maternal aversion ("withdrawal") by the mother in responding to the changing characteristics of the young. At the neural circuit level, the decline in maternal motivation is mediated by the excitatory ("approach") maternal neural circuit (e.g., MPOA and MPFC), which is increasingly being inhibited by the inhibitory ("withdrawal") neural circuit (the OB, ME, $\mathrm{VMH}$ and $\mathrm{DMH}$, etc.). The functional reorganization of both neurocircuits induced by hormones and maternal experience is the main driving force for the change of maternal behavior across postpartum. Neurochemically, we suggest that progesterone, melaninconcentrating hormone, and possibly other neurochemicals, such as prolactin, oxytocin and certain monoamines (dopamine and serotonin) play a role in the maternal behavior decline by tipping the balance between the excitatory and inhibitory neural circuits and synchronizing the mother-infant interaction. They, together with pup stimulation, act upon both neurocircuits to promote the avoidance and withdrawal responses, while suppress maternal caregiving responses. 


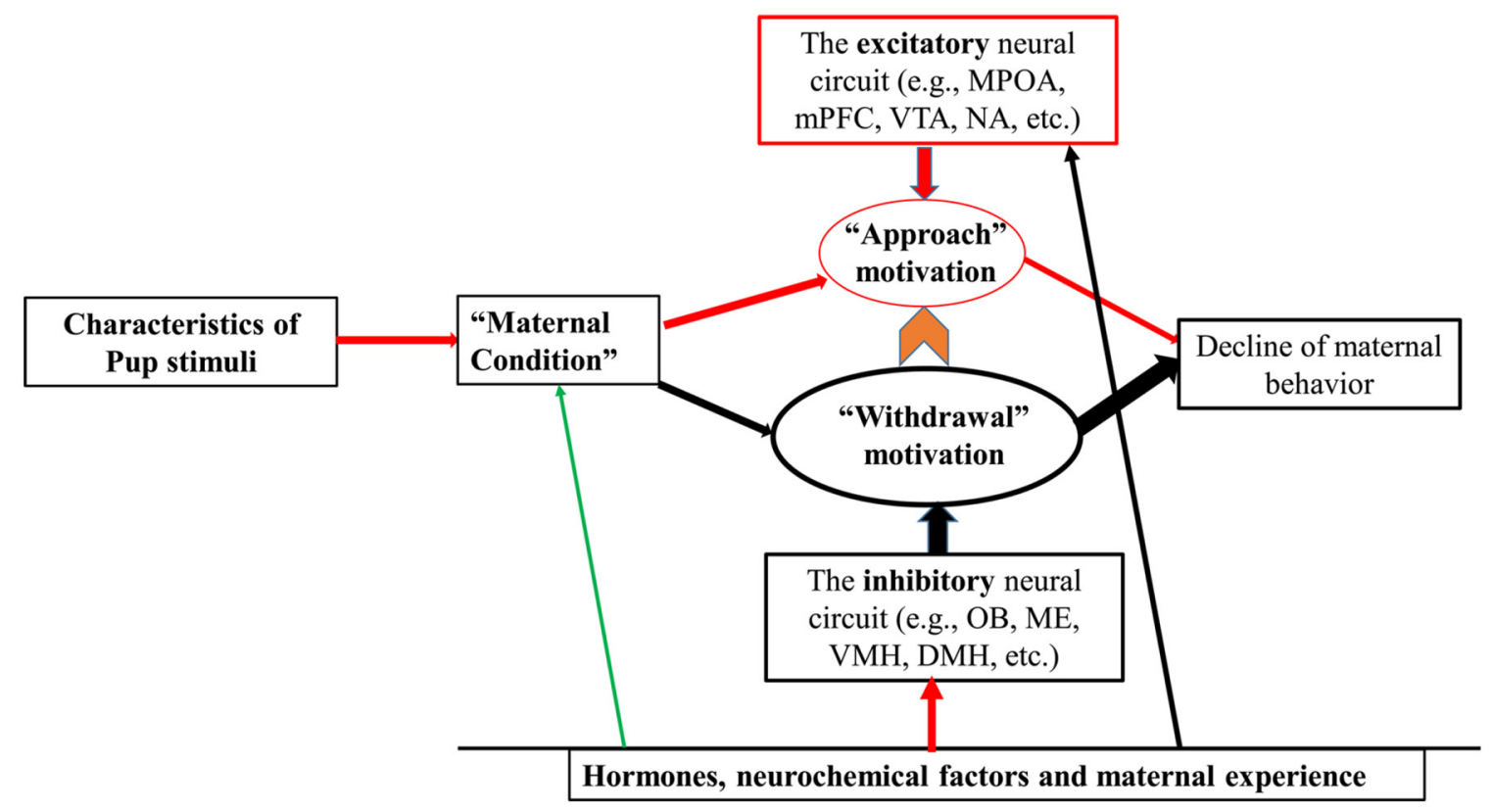

Fig. 3. A theoretical framework depicts the regulatory factors and neural networks involved in the regulation of the maternal behavior decline. In late postpartum, the decline in maternal care is instigated by the waning of maternal motivation (red thin line), coupled with the increased maternal aversion (black thick line) by the mother in responding to the changing characteristics of the young. The decline in maternal motivation is mediated by the excitatory ("approach") maternal neural circuit (e.g., MPOA and mPFC, VTA, NAc, etc.), which is increasingly being inhibited by the inhibitory ("withdrawal") neural circuit (the OB, ME, VMH and DMH, etc.). Hormones and other neurochemicals play a role in the maternal behavior decline by tipping the balance between the excitatory and inhibitory neural circuits and synchronizing the mother-infant interaction. MPOA: medial preoptic area; mPFC: medial prefrontal cortex; VTA: ventral tegmental area; NAc: nucleus accumbens; OB: olfactory bulb; ME: medial amygdala; VMH: ventromedial hypothalamus; $\mathrm{DMH}$ : dorsomedial hypothalamus.

More experimental studies are needed to test this model and provide a detailed description of how different factors (sensory, hormonal, and neurochemical) act together to generate neuronal signals to initiate and guide the maternal behavior decline. It is also important to elucidate the sub-neurocircuits within the "excitatory" and "inhibitory" neural networks and their neurochemistry. How the "approach" and "withdrawal" neural circuits interact throughout postpartum, especially in the decline phase is particularly important in determining the neurocircuit mechanisms underlying the decline of maternal behavior. Here we advocate an empirical approach to study the behavioral and neurobiological mechanisms underlying the maternal 
behavior decline. As the maternal behavior decline reflects the dynamic interplay between the female and the young, this approach considers both factors in a $2 \times 2$ complete factorial design with pup characteristics (young vs. old pups) and maternal condition (early vs. late postpartum) as two independent factors (Table 1). Grieb et al. (2018) used this paradigm and demonstrated that changes in maternal behavior across postpartum are elicited by what they called the "endogenous factors" in the dams and age-related sensory cues they receive from offspring, and their interactions. One major difference between this approach and those used to in the study of the onset and maintenance of maternal behavior is that the female's behaviors reflecting their withdrawal and rejection of the pups will also be recorded, in addiction to maternal behavior, so we will have two sets of dependent measures (Reisbick et al., 1975), indicative the activity of the "approach" and "withdrawal" systems.

In a typical study, each subject will be tested for the maternal "approach" behavior (e.g., pup approach, pup retrieval, licking, nest building, nursing, etc.) and maternal "withdrawal" behavior (e.g., maternal withdrawal, rejection, and prevention of nursing, etc.) with young (4-8 days old) and old (13-17 days old) pups in either early postpartum (3-7 postpartum days) or late postpartum (13-17 postpartum days) period. Testing pups should be acquired from donor mothers to ensure the consistency of pup stimuli. Depending on the research goals, they can be used acutely or repeatedly. In the latter case, the age of testing pups can be kept the same day by day, or be advanced by one day at a time throughout the testing period. Subjects could be tested in a variety of different behavioral tasks, such as home-cage maternal behavior testing (Grieb et al., 2018), conditioned place preference (or aversion) (Wansaw et al., 2008), pup preference (Gao et al., 2020; Li et al., 2018; Wu et al., 2018), and operant responding for pups or pup-related cues (Lee et al., 2000) to assess the motivational mechanisms underlying the maternal behavior decline.

Utilization of this approach is critical for the elucidation of the relevant behavioral, neurochemical and neural basis of the maternal behavior decline. A series of key questions can be addressed using this factorial design. For example, our model suggests that during the decline phase, the "inhibitory" neural circuit exerts an inhibition of the "excitatory" maternal neural circuit. No such evidence is available. Using this approach, if we can demonstrate that early postpartum females have higher neural activity (as measured in rodent neuroimaging, electrophysiological recording, or c-Fos immunohistochemistry, etc.) in the "excitatory" neural circuit, and lower neural activity in the "inhibitory" neural circuit when tested with young pups, but the opposite is true when tested with old pups, it would confirm that there are indeed dynamic changes of the function of the "excitatory" and "inhibitory" neural 
circuits across postpartum and such changes are sensitive to pup stimuli. Similarly, a demonstration that late postpartum females have lower neural activity in the "excitatory" neural circuit, and higher neural activity in the "inhibitory" neural circuit when tested with old pups, but the opposite is true when tested with young pups will additionally support our model. In regards to the neurochemical mechanisms, we can start with carefully monitoring neurochemical signals (as measured in microdialysis, voltammetry, viral biosensors, in situ hybridization, immunohistochemistry, etc.) in major components of the "excitatory" and "inhibitory" neural circuits across different stages of the maternal behavior cycle to identify the relevant changes associated with changes of maternal responsiveness. Furthermore, to gain celland pathway-specific circuit-level understanding of neurochemical mechanisms, we can manipulate a specific neuroreceptor (e.g., $\mathrm{D}_{1}, \mathrm{D}_{2}, 5-\mathrm{HT}_{2 \mathrm{~A}}$ or $5-\mathrm{HT}_{2 \mathrm{C}}$ ) in a particular brain region (e.g., mPFC or VTA) within the "excitatory" and "inhibitory" neural circuits in early and late postpartum periods.

\section{Implications for human parental care and mental disorders in children and mothers}

\subsection{Implications for human parental care}

The above reviewed animal studies on the behavioral and neurobiological mechanisms underlying the maternal behavior decline may aid in our understanding of human maternal behavior and in the clinical treatment of parenting disorders. This issue is particularly important as the period of human parenting is extended much longer relative to other mammals due to the prolonged period of immaturity and dependency. Thus, in order to ensure a child is able to grow and reach sexual maturity, parents have to allocate a large amount of effort and resources over decades, which can be otherwise invested in other offspring or on their own. At a certain point, when the costs of parental investment overweigh the benefits, parents will be pressured to decrease their parental care and start the decline phase of parental care. The withdrawal of maternal care is also a long-term process. Similar to animal research literature, the vast majority of studies have been focusing on pregnancy and early peripartum period (e.g., from pregnancy to parenthood) in an attempt to identify the psychological, social, endocrinal, and neurobiological changes that prepare parents for parenthood (Kim, 2016). Little research has examined the factors and mechanisms that control the decrease of parental care. Because of this unfortunate state of the science, we do not know much about the psychosocial factors and neural mechanisms associated with the natural progression of maternal care decline. In this section, we will use human weaning as an 
example to illustrate how our extended approach-withdrawal model can be applied to explain human weaning and point out the direction of future research. It should be noted that there is virtually no study that has examined the neurobiological mechanisms underlying weaning, thus our discussion will be focused on the possible psychological and hormonal influences on human weaning. Surely a full analysis of the process of weaning in the attachment and parental care context is beyond the scope of this review. There is a large body of literature on the regulation of breastfeeding and its impacts on child's development. Interested readers are referred to some excellent reviews on this topic (Crespi, 2011; Krol and Grossmann, 2018; Olza-Fernandez et al., 2014).

Weaning represents a critical period of time when mothers deliberately reduce one important component of maternal care - lactating. This is a period when the parent-offspring conflict may arise (Trivers, 1974). Parents and their children are expected to disagree over the duration of nursing, with children selected to seek a longer duration of nursing than mothers are selected to provide (Schlomer et al., 2011). Thus, the optimal duration of nursing differs from the perspectives of parents and children. Infant cues that mothers rely on to initiate the weaning process include the age and sensorimotor capacity of the infant, especially self-feeding.

"Maternal conditions" that signal the beginning of weaning time usually include resumption of sexual relations and pregnancy. In many societies, weaning typically occurs when the mother becomes pregnant, and pregnancy usually coincides with a decrease in nursing (Konner, 2005).

Ecologically speaking, resumption of sexual relations and pregnancy represent a transition point where reproductive effort is being diverted away from current maternal investment to future maternal investment. Biologically, events such as the resumption of sexual activity and pregnancy indicate changes in levels of sex hormones, especially progesterone. Could human progesterone contribute to weaning, as it does in decreasing the maternal behavior in rats and rabbits? Mothers invent various weaning practices to discourage nursing, including application of substances to the mother's nipples (Gray, 1996), or to simply leave the child in the care of others for a few hours or a few days in the absence of the mothers. These practices bear some resemblance to the "withdrawal" responses seen in animals. It should be noted that although weaning entails a substantial decrease in various maternal activities (e.g., lactating), it does not necessarily lead to any decrease in the emotional aspect of maternal love or loosening the parent-infant bonding. This explains why even after weaning, mothers still love their children and are strongly attached to them. 
10.2. Disruption of the decline of maternal behavior affects the health of the offspring and mothers

Many animal and human studies have demonstrated that quality and quantity of maternal care have a profound and long-lasting impact on the emotional, cognitive, social development of the child, and the development of later psychopathology. This section will mainly touch on how disruption of the normal decline in human maternal care in postpartum influences the wellbeing of a child. Two kinds of disruption are possible: speeded decline vs. delayed decline. Speeded decline will inevitably cause inadequate maternal care. Since there is voluminous research on how maternal deficits in the forms of maternal deprivation, neglect, abuse or abandonment etc., as part of early life experience, influence the physical and psychological development of the child (Bowlby, 1951), we will instead focus on how a delayed decline in maternal care, resulting in excessive maternal care, influences the mental health of the child.

Excessive maternal care of children is synonymous with maternal overprotection (Levy, 1938, 1945, Levy, 1966) (but see (Parker and Lipscombe, 1981). Maternal overprotection is associated with a style of mothering characterized by controlling, demanding, intrusive, highly supervising and vigilant behaviors (Thomasgard and Metz, 1993). Research has shown that maternal overprotection may be a causal factor promoting youth anxiety disorders and behavior problems (Gere et al., 2012; McLeod et al., 2007). David Levy has made the most significant contribution in delineating characteristics and determinants of maternal overprotection. After a careful study of mother cases with pronounced overprotective attitudes and behaviors, he classified the manifestations of maternal overprotection in three forms of maternal activity: excessive contact ("the mother is always there"), infantization ("she still treats him like a baby"), and prevention of independent behavior ("she won't let him grow up", or "she won't take any risks."). Research has revealed that mothers with maternal overprotection have certain characteristics (can be viewed as "maternal conditions" mentioned above). Levy suggested that overprotective mothers might be "naturally maternal" (high maternal drive) and were hungry for love. They may have been deprived of parental love in their early childhood and enjoyed caring for younger siblings. Parker and Lipscombe (1981) reported that overprotective mothers tended to possess marked maternal preoccupations before having children and exhibited overprotective mothering, and had personality characteristics of high anxiety, obsessionality and a need to control. They suggested that it might be possible to identify the potentially overprotective mothers based on their personality characteristics of high anxiety, obsessionality and need for control. This would have important clinical implications, as primary 
prevention and treatment programs can be developed to target these personality traits to improve the mental health in such mothers and their children. Studying how mothers with maternal overprotection respond to infant cues differently from non-overprotection mothers using various brain imaging tools would greatly enhance our understanding of the brain mechanisms involved in the regulation of maternal decline. Such a study is surely needed.

\section{Summary}

This review is intended to draw attention to an important stage of the postpartum maternal behavior cycle: the decline phase. We review limited empirical research on the roles of the young and mother in initiating the declining process and propose a multi-level model that is based on the parent-offspring conflict theory and the approach-withdrawal model. This model emphasizes the dynamic changes in two opposing motivational systems, and has an advantage of explaining all three phases of the maternal behavior cycle. At the beginning, adequate maternal care is critical to the survival of the young. The "approach" behavioral system is dominant, while the "withdrawal" response is being suppressed. When the young reach a certain age and when they gain more motor function, the decline of maternal behavior becomes necessary as it is important for the wellbeing of the young and reproductive success of the mother. At this stage, the "approach" behavioral system is gradually being suppressed, while the "withdrawal" system becomes dominant. Two specialized neural circuits that receive sensory, hormonal, and neuronal signals drive these two opposing motivated responses. The relative strength of these two neural systems changes across the three stages of the maternal behavior cycle and dictates behavioral outputs (i.e., approach or withdrawal). Changes in the neuronal functions are instigated by changing characteristics of the young (e.g., visual, auditory, tactile, etc.), maternal hormonal factors (e.g., progesterone, $\mathrm{MCH}$, prolactin), and maternal experiences. One thing to note is that the behavioral, hormonal, neurochemical and neural processes involved in the onset and maintenance of maternal behavior are in many ways also involved in the decline of this behavior, which means that they can be studied in a common framework.

This paper makes a case that understanding how the decline of maternal behavior is regulated behaviorally and neurobiologically is just as important as understanding how it is initiated and maintained, as it clearly aids our understanding of the physical and psychological development of the young and mother-infant interactions and bonding. Complications such as youth and maternal mental health issues caused by dysregulation of maternal care are multiple, some of which could be conceptualized as the consequences of inadequate regulation of maternal behavior decline. In this respect, future 
work focusing on the behavioral and neurobiological mechanisms underpinning the maternal behavior decline will shed more light on the parentyoung relations and the long-term consequences when the decline process is derailed. Ultimately, such knowledge will be valuable for developing new strategies to improve the wellbeing of mothers and their offspring.

Acknowledgments - I would like to thank Jonathan Li for proofreading and editing this manuscript. I also like to thank the National Institutes of Health for its support of my maternal behavior research over the years.

\section{References}

Afonso, V.M., Sison, M., Lovic, V., Fleming, A.S., 2007. Medial prefrontal cortex lesions in the female rat affect sexual and maternal behavior and their sequential organization. Behav. Neurosci. 121, 515-526.

Agid, O., Shapira, B., Zislin, J., Ritsner, M., Hanin, B., Murad, H., Troudart, T., Bloch, M., Heresco-Levy, U., Lerer, B., 1999. Environment and vulnerability to major psychiatric illness: a case control study of early parental loss in major depression, bipolar disorder and schizophrenia. Mol. Psychiatry 4, 163-172.

Alberts, J.R., Gubernick, D.J., 199o. Functional organization of dyadic and triadic parentoffspring systems, mammalian parenting. Biochemical, Neurobiological, and Behavioral Determinants. Oxford University Press, New York, NY, US, pp. 416-440.

Amenomori, Y., Chen, C.L., Meites, J., 1970. Serum prolactin levels in rats during different reproductive states. Endocrinology 86, 506-510.

Anastasio, N.C., Stutz, S.J., Fink, L.H., Swinford-Jackson, S.E., Sears, R.M., DiLeone, R.J., Rice, K.C., Moeller, F.G., Cunningham, K.A., 2015. Serotonin (5HT) 5-HT2A receptor (5-HT2AR):5-HT2CR imbalance in medial prefrontal cortex associates with motor impulsivity. ACS Chem. Neurosci. 6, 1248-1258.

Aponte, Y., Atasoy, D., Sternson, S.M., 2011. AGRP neurons are sufficient to orchestrate feeding behavior rapidly and without training. Nat. Neurosci. 14, 351-355.

Benedetto, L., Pereira, M., Ferreira, A., Torterolo, P., 2014. Melanin-concentrating hormone in the medial preoptic area reduces active components of maternal behavior in rats. Peptides 58, 20-25.

Berridge, K.C., 2007. The debate over dopamine's role in reward: the case for incentive salience. Psychopharmacology (Berl.) 191, 391-431.

Berridge, K.C., Robinson, T.E., 1998. What is the role of dopamine in reward: hedonic impact, reward learning, or incentive salience? Brain Res. Brain Res. Rev. 28, 309-369.

Bindra, D., 1969. A unified interpretation of emotion and motivation. Ann. N. Y. Acad. Sci. 159, 1071. 
Birke, L.I., Sadler, D., 1987. Differences in maternal behavior of rats and the sociosexual development of the offspring. Dev. Psychobiol. 20, 85-99.

Bowlby, J., 1951. Maternal Care and Mental Health: a Report Prepared on Behalf of the World Health Organization As a Contribution to the United Nations Programme for the Welfare of Homeless Children. World Health Organization, Geneva.

Bridges, R.S., Numan, M., Ronsheim, P.M., Mann, P.E., Lupini, C.E., 1990. Central prolactin infusions stimulate maternal behavior in steroid-treated, nulliparous female rats. Proc. Nat. Acad. Sci. U.S.A 87, 8003-8007.

Bridges, R.S., Mann, P.E., Coppeta, J.S., 1999. Hypothalamic involvement in the regulation of maternal behaviour in the rat: inhibitory roles for the ventromedial hypothalamus and the dorsal/anterior hypothalamic areas. J. Neuroendocrinol. 11, 259-266.

Brockington, I.F., Aucamp, H.M., Fraser, C., 2006. Severe disorders of the motherinfant relationship: definitions and frequency. Arch. Womens Ment. Health 9, 243-251.

Byrnes, E.M., Rigero, B.A., Bridges, R.S., 2002. Dopamine antagonists during parturition disrupt maternal care and the retention of maternal behavior in rats. Pharmacol. Biochem. Behav. 73, 869-875.

Caughey, S.D., Klampfl, S.M., Bishop, V.R., Pfoertsch, J., Neumann, I.D., Bosch, O.J., Meddle, S.L., 2011. Changes in the intensity of maternal aggression and central oxytocin and vasopressin V1a receptors across the peripartum period in the rat. J. Neuroendocrinol. 23, 1113-1124.

Champagne, D.L., Bagot, R.C., van Hasselt, F., Ramakers, G., Meaney, M.J., de Kloet, E.R., Joels, M., Krugers, H., 2008. Maternal care and hippocampal plasticity: evidence for experience-dependent structural plasticity, altered synaptic functioning, and differential responsiveness to glucocorticoids and stress. J. Neurosci. 28, 6037-6045.

Claessens, S.E., Daskalakis, N.P., van der Veen, R., Oitzl, M.S., de Kloet, E.R., Champagne, D.L., 2011. Development of individual differences in stress responsiveness: an overview of factors mediating the outcome of early life experiences. Psychopharmacology (Berl.) 214, 141-154.

Connor, J.R., Davis, H.R., 1980. Postpartum estrus in Norway rats. I. Behavior. Biol Reprod 23, 994-999.

Cramer, C.P., Thiels, E., Alberts, J.R., 1990. Weaning in rats: I. Maternal behavior. Dev. Psychobiol. 23, 479-493.

Crespi, B., 2011. The evolutionary biology of child health. Proc. Biol. Sci. 278, 1441-1449.

Dewsbury, D.A., Evans, R.L., Webster, D.G., 1979. Pregnancy initiation in postpartum estrus in three species of muroid rodents. Horm. Behav. 13, 1-8.

Dollinger, M.J., Holloway, W.R., Denenberg, V.H., 1980. Parturition in the rat (Rattus norvegicus): normative aspects and the temporal patterning of behaviours. Behav. Processes 5, 21-37. 
Escalada, J., Cacicedo, L., Ortego, J., Melian, E., Sanchez-Franco, F., 1996. Prolactin gene expression and secretion during pregnancy and lactation in the rat: role of dopamine and vasoactive intestinal peptide. Endocrinology 137, 631-637.

Fang, Y.Y., Yamaguchi, T., Song, S.C., Tritsch, N.X., Lin, D., 2018. A hypothalamic midbrain pathway essential for driving maternal behaviors. Neuron 98 (192207), e110.

Farshim, P., Walton, G., Chakrabarti, B., Givens, I., Saddy, D., Kitchen, I., Swann, Jonathan R., Bailey, A., 2016. Maternal weaning modulates emotional behavior and regulates the gut-brain Axis. Sci. Rep. 6, 21958.

Featherstone, R.E., Fleming, A.S., Ivy, G.O., 200o. Plasticity in the maternal circuit: effects of experience and partum condition on brain astroctye number in female rats. Behav. Neurosci. 114, 158-172.

Ferreira, A., Hansen, S., 1986. Sensory control of maternal aggression in Rattus norvegicus. J Comp Psychol 100, 173-177.

Ferreira, J.G.P., Bittencourt, J.C., Adamantidis, A., 2017. Melanin-concentrating hormone and sleep. Curr. Opin. Neurobiol. 44, 152-158.

Fleming, A.S., 1987. Psychobiology of rat maternal behavior: how and where hormones act to promote maternal behavior at parturition. In: Komisaruk, B.R., Siegel, H.I., Cheng, M.-F., Feder, H.H. (Eds.), Reproduction: A Behavioral and Neuroendocrine Perspective. New York Academy of Sciences, New York, pp. 234-251.

Fleming, A.S., 2007. The three faces of Jay S. Rosenblatt. Dev. Psychobiol. 49, 2-11.

Fleming, A.S., Corter, C., 1988. Factors influencing maternal responsiveness in humans: usefulness of an animal model. Psychoneuroendocrinology 13, 189-212.

Fleming, A.S., Luebke, C., 1981. Timidity prevents the virgin female rat from being a good mother: emotionality differences between nulliparous and parturient females. Physiol. Behav. 27, 863-868.

Fleming, A.S., Rosenblatt, J.S., 1974a. Maternal behavior in the virgin and lactating rat. J. Comp. Physiol. Psychol. 86, 957-972.

Fleming, A.S., Rosenblatt, J.S., 1974b. Olfactory regulation of maternal behavior in rats. I. Effects of olfactory bulb removal in experienced and inexperienced lactating and cycling females. Journal of Comparative and Physiological Psychology 86, 221-232.

Fleming, A.S., Rosenblatt, J.S., 1974c. Olfactory regulation of maternal behavior in rats. II. Effects of peripherally induced anosmia and lesions of the lateral olfactory tract in pup-induced virgins. J. Comp. Physiol. Psychol. 86, 233-246.

Fleming, A., Vaccarino, F., Tambosso, L., Chee, P., 1979. Vomeronasal and olfactory system modulation of maternal behavior in the rat. Science 203, 372-374.

Fleming, A.S., Vaccarino, F., Luebke, C., 1980. Amygdaloid inhibition of maternal behavior in the nulliparous female rat. Physiol. Behav. 25, 731-743.

Fleming, A.S., Miceli, M., Moretto, D., 1983. Lesions of the medial preoptic area prevent the facilitation of maternal behavior produced by amygdala lesions. Physiol. Behav. 31, 503-510. 
Fleming, A.S., Cheung, U., Myhal, N., Kessler, Z., 1989. Effects of maternal hormones on' timidity' and attraction to pup-related odors in female rats. Physiol. Behav. 46, 449-453.

Fleming, A.S., Gavarth, K., Sarker, J., 1992. Effects of transections to the vomeronasal nerves or to the main olfactory bulbs on the initiation and longterm retention of maternal behavior in primiparous rats. Behav. Neural Biol. $57,177-188$.

Galef, B.G., 1981. The ecology of weaning-parasitism and the achievement of independence by altricial mammals. In: Gubernick, D.J., Klopfer, P.H. (Eds.), Parental Care in Mammals. Plenum Press, New York.

Gao, J., Nie, L., Li, Y., Li, M., 202O. Serotonin 5-HT2A and 5-HT2C receptors regulate rat maternal behavior through distinct behavioral and neural mechanisms. Neuropharmacology 162, 107848.

Gardner, C.R., Phillips, S.W., 1977. The influence of the amygdala on the basal septum and preoptic area of the rat. Exp. Brain Res. 29, 249-263.

Gere, M.K., Villabo, M.A., Torgersen, S., Kendall, P.C., 2012. Overprotective parenting and child anxiety: the role of co-occurring child behavior problems. J. Anxiety Disord. 26, 642-649.

Gilbert, A.N., 1984. Postpartum and lactational estrus: a comparative analysis in rodentia. J Comp Psychol 98, 232-245.

Gonzalez-Mariscal, G., Gallegos, J.A., 2014. The maintenance and termination of maternal behavior in rabbits: involvement of suckling and progesterone. Physiol. Behav. 124, 72-76.

González-Mariscal, G., Gallegos, J.A., Sierra-Ramirez, A., Flores, J.G., 2009. Impact of concurrent pregnancy and lactation on maternal nest- building, estradiol and progesterone concentrations in rabbits. World Rabbit Sci. 17, 145-152.

Gonzalez-Mariscal, G., Caba, M., Martinez-Gomez, M., Bautista, A., Hudson, R., 2016. Mothers and offspring: the rabbit as a model system in the study of mammalian maternal behavior and sibling interactions. Horm. Behav. 77, 30-41.

Gordon, I., Zagoory-Sharon, O., Leckman, J.F., Feldman, R., 2010. Oxytocin and the development of parenting in humans. Biol Psychiat 68, 377-382.

Gray, S.J., 1996. Ecology of weaning among nomadic Turkana pastoralists of Kenya: maternal thinking, maternal behavior, and human adaptive strategies. Hum. Biol. 68, 437-465.

Grieb, Z.A., Tierney, S.M., Lonstein, J.S., 2017. Postpartum inhibition of ovarian steroid action increases aspects of maternal caregiving and reduces medial preoptic area progesterone receptor expression in female rats. Horm. Behav. 96, 31-41.

Grieb, Z.A., Holschbach, M.A., Lonstein, J.S., 2018. Interaction between postpartum stage and litter age on maternal caregiving and medial preoptic area orexin. Physiol. Behav. 194, 430-436.

Grieb, Z.A., Vitale, E.M., Morrell, J.I., Lonstein, J.S., Pereira, M., 2020. Decreased mesolimbic dopaminergic signaling underlies the waning of maternal caregiving across the postpartum period in rats. Psychopharmacology (Berl.). 
Hansen, S., 1994. Maternal behavior of female rats with 6-OHDA lesions in the ventral striatum: characterization of the pup retrieval deficit. Physiol. Behav. 55, 615-620.

Hauser, H., Gandelman, R., 1985. Lever pressing for pups: evidence for hormonal influence upon maternal behavior of mice. Horm. Behav. 19, 454-468.

Heidbreder, C.A., Groenewegen, H.J., 2003. The medial prefrontal cortex in the rat: evidence for a dorso-ventral distinction based upon functional and anatomical characteristics. Neurosci. Biobehav. Rev. 27, 555-579.

Holschbach, M.A., Vitale, E.M., Lonstein, J.S., 2018. Serotonin-specific lesions of the dorsal raphe disrupt maternal aggression and caregiving in postpartum rats. Behav. Brain Res. 348, 53-64.

Hudson, R., Bilko, A., Altbacker, V., 1996. Nursing, weaning and the development of independent feeding in the rabbit (Oryctolagus cuniculus). Z. Saugetierkd. $61,39-48$.

Keer, S.E., Stern, J.M., 1999. Dopamine receptor blockade in the nucleus accumbens inhibits maternal retrieval and licking, but enhances nursing behavior in lactating rats. Physiol. Behav. 67, 659-669.

Kikusui, T., Kanbara, N., Ozaki, M., Hirayama, N., Ida, K., Tokita, M., Tanabe, N., Mitsuyama, K., Abe, H., Yoshida, M., Nagasawa, M., Mogi, K., 2019. Early weaning increases anxiety via brain-derived neurotrophic factor signaling in the mouse prefrontal cortex. Sci. Rep. 9, 3991.

Kim, P., 2016. Human maternal brain plasticity: adaptation to parenting. New Dir. Child Adolesc. Dev. 2016, 47-58.

Knollema, S., Brown, E.R., Vale, W., Sawchenko, P.E., 1992. Novel hypothalamic and preoptic sites of prepro-melanin-concentrating hormone messenger ribonucleic Acid and Peptide expression in lactating rats. J. Neuroendocrinol. 4, 709-717.

Kohl, J., Dulac, C., 2018. Neural control of parental behaviors. Curr. Opin. Neurobiol. 49, 116-122.

Kohl, J., Autry, A.E., Dulac, C., 2017. The neurobiology of parenting: a neural circuit perspective. Bioessays 39, 1-11.

Kohl, J., Babayan, B.M., Rubinstein, N.D., Autry, A.E., Marin-Rodriguez, B., Kapoor, V., Miyamishi, K., Zweifel, L.S., Luo, L., Uchida, N., Dulac, C., 2018. Functional circuit architecture underlying parental behaviour. Nature 556, 326-331.

Konig, B., Markl, H., 1987. Maternal-care in house mice .1. The weaning strategy as a means for parental manipulation of offspring quality. Behav. Ecol. Sociobiol. (Print) 20, 1-9.

Krol, K.M., Grossmann, T., 2018. Psychological effects of breastfeeding on children and mothers. Bundesgesundheitsblatt Gesundheitsforschung Gesundheitsschutz 61, 977-985.

Lee, A., Clancy, S., Fleming, A.S., 200o. Mother rats bar-press for pups: effects of lesions of the mpoa and limbic sites on maternal behavior and operant responding for pup-reinforcement. Behav. Brain Res. 108, 215-231.

Levy, D.M., 1938. Maternal overprotection. Psychiatry 1, 561-591. 
Levy, D.M., 1945. Maternal Overprotection. Columbia University Press, New York.

Levy, D.M., 1966. Maternal Overprotection. Norton, New York.

Li, M., 2015. Antipsychotic drugs on maternal behavior in rats. Behav. Pharmacol. 26, 616-626.

Li, M., Chou, S.Y., 2016. Modeling postpartum depression in rats: theoretic and methodological issues. Dongwuxue Yanjiu 37, 229-236.

Li, M., Fleming, A.S., 2003. The nucleus accumbens shell is critical for normal expression of pup-retrieval in postpartum female rats. Behav. Brain Res. 145, 99-111.

Li, X., Ding, X., Wu, R., Chen, L., Gao, J., Hu, G., Li, M., 2018. A behavioral mechanistic investigation of the role of 5-HT1A receptors in the mediation of rat maternal behavior. Pharmacol. Biochem. Behav. 169, 16-26.

Li, X.Y., Han, Y., Zhang, W., Wang, S.R., Wei, Y.C., Li, S.S., Lin, J.K., Yan, J.J., Chen, A.X., Zhang, X., Zhao, Z.D., Shen, W.L., Xu, X.H., 2019. AGRP neurons project to the medial preoptic area and modulate maternal nest-building. J. Neurosci. 39, 456-471.

Liu, D., Diorio, J., Tannenbaum, B., Caldji, C., Francis, D., Freedman, A., Sharma, S., Pearson, D., Plotsky, P.M., Meaney, M.J., 1997. Maternal care, hippocampal glucocorticoid receptors, and hypothalamic- pituitary-adrenal responses to stress [see comments]. Science 277, 1659-1662.

Liu, D., Diorio, J., Day, J.C., Francis, D.D., Meaney, M.J., 200o. Maternal care, hippocampal synaptogenesis and cognitive development in rats. Nat. Neurosci. 3, 799-806.

Lonstein, J.S., Stern, J.M., 1997a. Role of the midbrain periaqueductal gray in maternal nurturance and aggression: c-fos and electrolytic lesion studies in lactating rats. J. Neurosci. 17, 3364-3378.

Lonstein, J.S., Stern, J.M., 1997b. Somatosensory contributions to c-fos activation within the caudal periaqueductal gray of lactating rats: effects of perioral, rooting, and suckling stimuli from pups. Horm. Behav. 32, 155-166.

Lonstein, J.S., Levy, F., Fleming, A.S., 2015. Common and divergent psychobiological mechanisms underlying maternal behaviors in non-human and human mammals. Horm. Behav. 73, 156-185.

Mann, P.E., Babb, J.A., 2004. Disinhibition of maternal behavior following neurotoxic lesions of the hypothalamus in primigravid rats. Brain Res. 1025, 51-58.

Martinez-Gomez, M., Juarez, M., Distel, H., Hudson, R., 2004. Overlapping litters and reproductive performance in the domestic rabbit. Physiol. Behav. 82, 629-636.

Mattson, B.J., Williams, S., Rosenblatt, J.S., Morrell, J.I., 2001. Comparison of two positive reinforcing stimuli: pups and cocaine throughout the postpartum period. Behav. Neurosci. 115, 683-694.

Mayer, A.D., Rosenblatt, J.S., 1987. Hormonal factors influence the onset of maternal aggression in laboratory rats. Horm. Behav. 21, 253-267. 
McLeod, B.D., Wood, J.J., Weisz, J.R., 2007. Examining the association between parenting and childhood anxiety: a meta-analysis. Clin. Psychol. Rev. 27, 155-172.

Moghaddam, B., Homayoun, H., 2008. Divergent plasticity of prefrontal cortex networks. Neuropsychopharmacology 33, 42-55.

Moltz, H., 1974. Some mechanisms governing the induction, maintenance, and synchrony of maternal behavior in the laboratory rat. Adv. Behav. Biol. 11, 77-96.

Moore, C.L., Morelli, G.A., 1979. Mother rats interact differently with male and female offspring. J. Comp. Physiol. Psychol. 93, 677-684.

Morgan, H.D., Fleming, A.S., Stern, J.M., 1992. Somatosensory control of the onset and retention of maternal responsiveness in primiparous Sprague-Dawley rats. Physiol. Behav. 51, 549-555.

Morgan, H.D., Watchus, J.A., Milgram, N.W., Fleming, A.S., 1999. The long lasting effects of electrical simulation of the medial preoptic area and medial amygdala on maternal behavior in female rats. Behav. Brain Res. 99, 61-73.

Numan, M., 1994. Maternal behavior. In: Knobil, E., Neill, J.D. (Eds.), The Physiology of Reproduction, 2nd ed. Raven Press, New York, pp. 221-302.

Numan, M., 2007. Motivational systems and the neural circuitry of maternal behavior in the rat. Dev. Psychobiol. 49, 12-21.

Numan, M., 2015. Neurobiology of social behavior. Toward an Understanding of the Prosocial and Antisocial Brain. Elsevier/AP, Academic Press is an imprint of Elsevier, London, UK; Waltham, MA.

Numan, M., Insel, T.R., 2003. The Neurobiology of Parental Behavior. Springer, New York.

Numan, M., Young, L.J., 2016. Neural mechanisms of mother-infant bonding and pair bonding: similarities, differences, and broader implications. Horm. Behav. 77, 98-112.

Numan, M., Numan, M.J., English, J.B., 1993. Excitotoxic amino acid injections into the medial amygdala facilitate maternal behavior in virgin female rats. Horm. Behav. 27, 56-81.

Numan, M., Bress, J.A., Ranker, L.R., Gary, A.J., Denicola, A.L., Bettis, J.K., Knapp, S.E., 2010. The importance of the basolateral/basomedial amygdala for goaldirected maternal responses in postpartum rats. Behav. Brain Res. 214, 368-376.

Olazabal, D.E., Pereira, M., Agrati, D., Ferreira, A., Fleming, A.S., GonzalezMariscal, G., Levy, F., Lucion, A.B., Morrell, J.I., Numan, M., Uriarte, N., 2013. New theoretical and experimental approaches on maternal motivation in mammals. Neurosci. Biobehav. Rev. 37, 186o-1874.

Olza-Fernandez, I., Marin Gabriel, M.A., Gil-Sanchez, A., Garcia-Segura, L.M., Arevalo, M.A., 2014. Neuroendocrinology of childbirth and mother-child attachment: the basis of an etiopathogenic model of perinatal neurobiological disorders. Front. Neuroendocrinol. 35, 459-472. 
Orpen, B.G., Furman, N., Wong, P.Y., Fleming, A.S., 1987. Hormonal influences on the duration of postpartum maternal responsiveness in the rat. Physiol. Behav. 40, 307-315.

Parker, G., Lipscombe, P., 1981. Influences of maternal overprotection. Br. J. Psychiatry 138, 303-311.

Pawluski, J.L., Li, M., Lonstein, J.S., 2019. Serotonin and motherhood: from molecules to mood. Front. Neuroendocrinol.

Pereira, M., Ferreira, A., 2006. Demanding pups improve maternal behavioral impairments in sensitized and haloperidol-treated lactating female rats. Behav. Brain Res. 175, 139-148.

Pereira, M., Ferreira, A., 2016. Neuroanatomical and neurochemical basis of parenting: dynamic coordination of motivational, affective and cognitive processes. Horm. Behav. 77, 72-85.

Pereira, M., Morrell, J.I., 2009. The changing role of the medial preoptic area in the regulation of maternal behavior across the postpartum period: facilitation followed by inhibition. Behav. Brain Res. 205, 238-248.

Pereira, M., Morrell, J.I., 2011. Functional mapping of the neural circuitry of rat maternal motivation: effects of site-specific transient neural inactivation. J. Neuroendocrinol. 23, 1020-1035.

Pereira, M., Uriarte, N., Agrati, D., Zuluaga, M.J., Ferreira, A., 2005. Motivational aspects of maternal anxiolysis in lactating rats. Psychopharmacology (Berl.) 180, 241-248.

Pereira, M., Farrar, A., Morrell, J., Abercrombie, E., 2013. Changes in nucleus accumbens dopamine release during mother-pup interactions at early and late postpartum stages. In: V Parental Brain Conference. Germany.

Pryce, C.R., 1992. A comparative systems model of the regulation of maternal motivation in mammals. Anim. Behav. 43, 417-441.

Puig, M.V., Gulledge, A.T., 2011. Serotonin and prefrontal cortex function: neurons, networks, and circuits. Mol. Neurobiol. 44, 449-464.

Puig, M.V., Gulledge, A.T., Lambe, E.K., Gonzalez-Burgos, G., 2015. Editorial: neuromodulation of executive circuits. Front. Neural Circuits 9, 58.

Reisbick, S., Rosenblatt, J.S., Mayer, A.D., 1975. Decline of maternal behavior in the virgin and lactating rat. J. Comp. Physiol. Psychol. 89, 722-732.

Robson, K.M., Kumar, R., 1980. Delayed onset of maternal affection after childbirth. Br. J. Psychiatry 136, 347-353.

Rondini, T.A., Donato Jr., J., Rodrigues Bde, C., Bittencourt, J.C., Elias, C.F., 2010. Chemical identity and connections of medial preoptic area neurons expressing melanin-concentrating hormone during lactation. J. Chem. Neuroanat. 39, 51-62.

Rosenblatt, J.S., 1967. Nonhormonal basis of maternal behavior in the rat. Science $156,1512-1514$.

Rosenblatt, J.S., 1969. The development of maternal responsiveness in the rat. Am. J. Orthopsychiatry 39, 36-56. 
Rosenblatt, J.S., 1989. The physiological and evolutionary background of maternal responsiveness. New Dir. Child Dev. 15-30.

Rosenblatt, J.S., 1990. Landmarks in the physiological study of maternal behavior with special reference to the rat. In: Krasnegor, N.A., Bridges, R.S. (Eds.), Mammalian Parenting: Biochemical, Neurobiological and Behavioural Determinants. Oxford University Press, New York, pp. 40-6o.

Rosenblatt, J.S., Lehrman, D.S., 1963. Maternal behavior in the laboratory rat. In: Rheingold, H.L. (Ed.), Maternal Behavior in Mammals. John Wiley \& Sons, Inc., New York, pp. 8-57.

Rosenblatt, J.S., Mayer, A.D., 1995. An analysis of approach/withdrawal processes in the initiation of maternal behavior. In: the laboratory rat, in:, Hood, K.E., Greenberg, G.E.T. (Eds.), Behavioral Development. Garland Press, New York, pp. 177-230.

Schiller, C.E., Johnson, S.L., Abate, A.C., Schmidt, P.J., Rubinow, D.R., 2016. Reproductive steroid regulation of mood and behavior. Compr. Physiol. 6, 1135-116o.

Schlomer, G.L., Del Giudice, M., Ellis, B.J., 2011. Parent-offspring conflict theory: an evolutionary framework for understanding conflict within human families. Psychol. Rev. 118, 496-521.

Schneirla, T.C., 1959. An evolutionary and developmental theory of biphasic process underlying approach and withdrawal. In: Jones, M.R. (Ed.), Nebraska Symposium on Motivation. University of Nebraska Press, Lincoln, pp. 1-42.

Scott, N., Prigge, M., Yizhar, O., Kimchi, T., 2015. A sexually dimorphic hypothalamic circuit controls maternal care and oxytocin secretion. Nature 525, 519-522.

Sheehan, T.P., Numan, M., 1997. Microinjection of the tachykinin neuropeptide K into the ventromedial hypothalamus disrupts the hormonal onset of maternal behavior in female rats. J. Neuroendocrinol. 9, 677-687.

Silva, M.R., Bernardi, M.M., Felicio, L.F., 2001. Effects of dopamine receptor antagonists on ongoing maternal behavior in rats. Pharmacol. Biochem. Behav. 68, 461-468.

Smith, L., Berkson, G., 1973. Litter stimulus factors in maternal retrieval (Rattus rattus). Anim. Behav. 21, 620-623.

Stern, J.M., 1989. Maternal behavior: sensory, hormonal, and neural determinants. In: Brush, F.R., Levine, S. (Eds.), Psychoendocrinology. Academic Press, New York, pp. 105-226.

Stern, J.M., 1990. Multisensory regulation of maternal behavior and masculine sexual behavior: a revised view. Neurosci Biobehav R 14, 183-200.

Stern, J.M., Keer, S.E., 1999. Maternal motivation of lactating rats is disrupted by low dosages of haloperidol. Behav. Brain Res. 99, 231-239.

Stern, J.M., Kolunie, J.M., 1989. Perioral anesthesia disrupts maternal behavior during early lactation in long-evans rats. Behav. Neural Biol. 52, 20-38.

Stern, J.M., Kolunie, J.M., 1991. Trigeminal lesions and maternal behavior in Norway rats: I. Effects of cutaneous rostral snout denervation on maintenance of nurturance and maternal aggression. Behav. Neurosci. 105, 984-997. 
Stern, J.M., Kolunie, J.M., 1993. Maternal aggression of rats is impaired by cutaneous anesthesia of the ventral trunk, but not by nipple removal. Physiol. Behav. 54, 861-868.

Stern, J.M., Dix, L., Bellomo, C., Thramann, C., 1992. Ventral trunk somatosensory determinants of nursing behavior in Norway rats: role of nipple and surrounding sensations. Psychobiology 20, 71-80.

Stolzenberg, D.S., Champagne, F.A., 2016. Hormonal and non-hormonal bases of maternal behavior: the role of experience and epigenetic mechanisms. Horm. Behav. 77, 204-210.

Stolzenberg, D.S., Numan, M., 2011. Hypothalamic interaction with the mesolimbic DA system in the control of the maternal and sexual behaviors in rats. Neurosci. Biobehav. Rev. 35, 826-847.

Tavares, G.A., do Amaral Almeida, L.C., de Souza, J.A., de Farias, V.V., de Souza, F.L., de Andrade Silva, S.C., Lagranha, C.J., Kaeffer, B., de Souza, S.L., 2020. Early weaning leads to disruption of homeostatic and hedonic eating behaviors and modulates serotonin (5HT) and dopamine (DA) systems in male adult rats. Behav. Brain Res. 383, 112531.

Taya, K., Greenwald, G.S., 1982. Peripheral blood and ovarian levels of sex steroids in the lactating rat. Endocrinol. Jpn. 29, 453-459.

Thomasgard, M., Metz, W.P., 1993. Parental overprotection revisited. Child Psychiatry Hum. Dev. 24, 67-80.

Toates, F.M., 1986. Motivational Systems. Cambridge University Press, Cambridge [Cambridgeshire], New York.

Trivers, R.L., 1974. Parent-offspring conflict. Am. Zool. 14, 249-264.

Uriarte, N., Ferreira, A., Rosa, X.F., Sebben, V., Lucion, A.B., 2008. Overlapping litters in rats: effects on maternal behavior and offspring emotionality. Physiol. Behav. 93, 1061-1070.

Uriarte, N., Fernandez, M.V., Agrati, D., Zuluaga, M.J., Ferreno, M., Ferreira, A., 2014. Maternal and affective behaviors of lactating rats reared in overlapping litters. J. Physiol. Paris 108, 221-230.

Wang, L., Chen, I.Z., Lin, D., 2015. Collateral pathways from the ventromedial hypothalamus mediate defensive behaviors. Neuron 85, 1344-1358.

Wansaw, M.P., Pereira, M., Morrell, J.I., 2008. Characterization of maternal motivation in the lactating rat: contrasts between early and late postpartum responses. Horm. Behav. 54, 294-301.

Wei, Y.C., Wang, S.R., Jiao, Z.L., Zhang, W., Lin, J.K., Li, X.Y., Li, S.S., Zhang, X., $\mathrm{Xu}, \mathrm{X} . \mathrm{H} .$, 2018. Medial preoptic area in mice is capable of mediating sexually dimorphic behaviors regardless of gender. Nat. Commun. 9, 279.

Winokur, S.B., Lopes, K.L., Moparthi, Y., Pereira, M., 2019. Depression-related disturbances in rat maternal behaviour are associated with altered monoamine levels within mesocorticolimbic structures. J. Neuroendocrinol. 31, e12766.

Wu, Z., Autry, A.E., Bergan, J.F., Watabe-Uchida, M., Dulac, C.G., 2014. Galanin neurons in the medial preoptic area govern parental behaviour. Nature 509, 325-330. 
Wu, R., Gao, J., Chou, S., Davis, C., Li, M., 2016. Behavioral, pharmacological and neuroanatomical analysis of serotonin $2 \mathrm{C}$ receptor agonism on maternal behavior in rats. Psychoneuroendocrinology 73, 252-262.

Wu, R., Davis, C., Li, M., 2018. Behavioral mechanisms underlying the maternal disruptive effect of serotonin 5-HT2A receptor activation in Sprague-Dawley rats. J Neural Transm (Vienna) 125, 1065-1075.

Yu, G.Z., Kaba, H., Okutani, F., Takahashi, S., Higuchi, T., 1996. The olfactory bulb: a critical site of action for oxytocin in the induction of maternal behaviour in the rat. Neuroscience 72, 1083-1088.

Zhao, C., Li, M., 2009. Sedation and disruption of maternal motivation underlie the disruptive effects of antipsychotic treatment on rat maternal behavior. Pharmacol. Biochem. Behav. 92, 147-156. 